\title{
The Economics of the Family and Its Policy Implications: Why Should We Care About Fertility Outcomes?
}

\author{
Martin Werding* \\ Revised version \\ March 2008
}

\begin{abstract}
This paper reviews potential explanations of the continued fertility decline in developed countries that are provided by the economic theory of the family and discusses their implications regarding the appropriateness of public interventions. Theoretical approaches covered are the quantity-quality interaction in parental fertility decisions; time-allocation models with rising opportunity costs of domestic child care; models of intra-household bargaining in which fertility choices affect bargaining positions of the partners involved; and models with intertemporal choices in which fiscal externalities of child-rearing activities arise from other public intervention into the field of intergenerational distribution. Based on these explanations, the reduction in average fertility may, to a considerable degree, reflect rational adaptations of (potential) parents to changes in their economic environment. At closer scrutiny, however, the second and third approach provide some justifications for government action to better frame the decisions taken at the micro level. The fourth approach definitely calls for corrective measures. The discussion also allows for some conclusions as to which broad categories of policy instruments might be needed in each case.
\end{abstract}

JEL code: $\mathrm{H} 31, \mathrm{H} 5 ; \mathrm{J} 1, \mathrm{~J} 22$

Keywords: Economics of the family, fertility decisions, children; time allocation, female labor supply; public policy, family policy, intergenerational redistribution

* Ifo Institute for Economic Research \& CESifo

Author's address:

Ifo Institute for Economic Research

Dept. of Social Policy and Labour Markets

Poschingerstrasse 5

81679 Munich, Germany

Telephone: $+(+49) 89$ 9224-1607

Telefax: $\quad+(+49) 89$ 9224-1608

Email: werding@ifo.de 


\section{The Economics of the Family and Its Policy Implications: Why Should We Care About Fertility Outcomes?}

\section{Introduction}

There is, as of now, no theory that is generally accepted and provides a comprehensive, causal explanation for the long-term fertility decline observed throughout the developed world. What comes closest to this standard is the "theory of demographic transition" (see Birg 1995, ch. 3) - a purely descriptive approach which refers to a characteristic sequence of reductions in (age-specific) mortality and fertility, with consequences for the growth rate as well as the age structure of the population affected that are easily predictable. So far, all data that are becoming available appear to fit to this pattern, so that demographers tend to assume that even many developing countries will follow the basic trends observed in developed ones, only with a time lag of several decades.

When economists entered the field of demography attempting to offer explanations for some of the facets of demographic development, they were seen as a horde of primitive invaders by researchers from many other disciplines. ${ }^{1}$ The incident seemed to be a typical case of "economic imperialism" with respect to issues which had been addressed by other social sciences beforehand. Since then, population economics and the economics of the family as one of its major branches have unfolded a broad research program, following an agenda that was mainly targeted at "positive" analyses, for instance, of how parents are making fertility choices and how these decisions may interfere with other household-level activities. Normative questions were largely outside the focus of this literature, at least for quite a while. Nevertheless, even if one abstracts from the intriguing question for a socially desirable, or "optimum", level of fertility, ${ }^{2}$ the differing economic models of individual fertility decisions which have been suggested to date do have a number of policy implications. The main purpose of this paper is to work out these implications building on the economic theory of "market failure", or institutional failure, in order to provide a sound basis for the discussion of why, in terms of reasonable concerns, we should care about fertility outcomes if they are essentially seen as a result of decentralized choices made by individuals who are acting rationally.

\footnotetext{
See Leibenstein (1974). This objection was directly aimed at the new fertility theory provided by the "Chicago school", most prominently by Nobel-laureate Gary S. Becker in his seminal 1960 paper (Becker 1960). Ironically, it was laid down by one of the few economists who had been working on demographic issues earlier than that.

2 That this question is technically complex can already be inferred from the controversy about Samuelson's $(1975 ; 1976)$ "serendipity theorem". At the same time, it involves a number of highly delicate conceptual issues which are discussed, for instance, in Razin and Sadka (1995, ch. 6) or Cigno and Werding (2007, ch. 7).
} 
The paper is organized as follows. Section 2 provides some empirical data illustrating the fertility decline in developed countries and briefly discusses whether its economic consequences that become visible at a macro level may constitute a case for government intervention. Section 3 summarizes the main mechanisms that have been suggested in the literature on family economics and may be operative at a micro level behind the reduction in average fertility in developed countries which has been observed over the last century. Section 4 discusses the policy implications arising from these theoretical analyses and takes a glance at broad categories of policy instruments which might be suited to address these issues. Section 5 concludes.

\section{Fertility Decline in Developed Countries}

\subsection{Stylized facts}

In the developed world, there has been a continuous decline in fertility since the late $19^{\text {th }}$ century. Essentially, this process has had two stages. In an initial phase which lasted until the inter-war period, the number of births typically fell from what now seem to be excessively high levels to a "replacement" level. The latter is a level of fertility that would have kept total population constant if it had been maintained over several decades and if other changes - above all in life expectancy and in net migration - had been absent. However, following the so-called "baby boom" in the early after-war period, fertility started declining once again in most industrialized countries and soon fell below this benchmark level. The speed and strength of this trend shows a considerable degree of variation across countries. But there are only a few exceptions, most notably the US and France, where fertility has recovered to a replacement level more recently.

At an aggregate level, fertility outcomes can be measured in several ways. The simplest way of making current fertility data comparable across countries is to relate them to the number of individuals that are already alive. The result, for example, the "crude birth rate" (CBR) reflecting the number of live births per 1,000 inhabitants in a given country and a given year, is a rough but rather telling measure for the general pattern of fertility decline (see Figure 1). It can be computed from data that are easily available for many countries, often over a long period of time. Also, as the nominator of this rate is given by the number of individuals actually born in a particular year, its development over time has a direct impact on the size as well as the current and future age composition of the entire population. However, using total population - or, as it is sometimes done, the female population only - as a denominator neglects the fact that not all of the existing individuals, nor even all of the existing women, are biologically capable of breeding children. 
Figure 1: Crude birth rates in OECD and non-OECD countries, 1900-2000

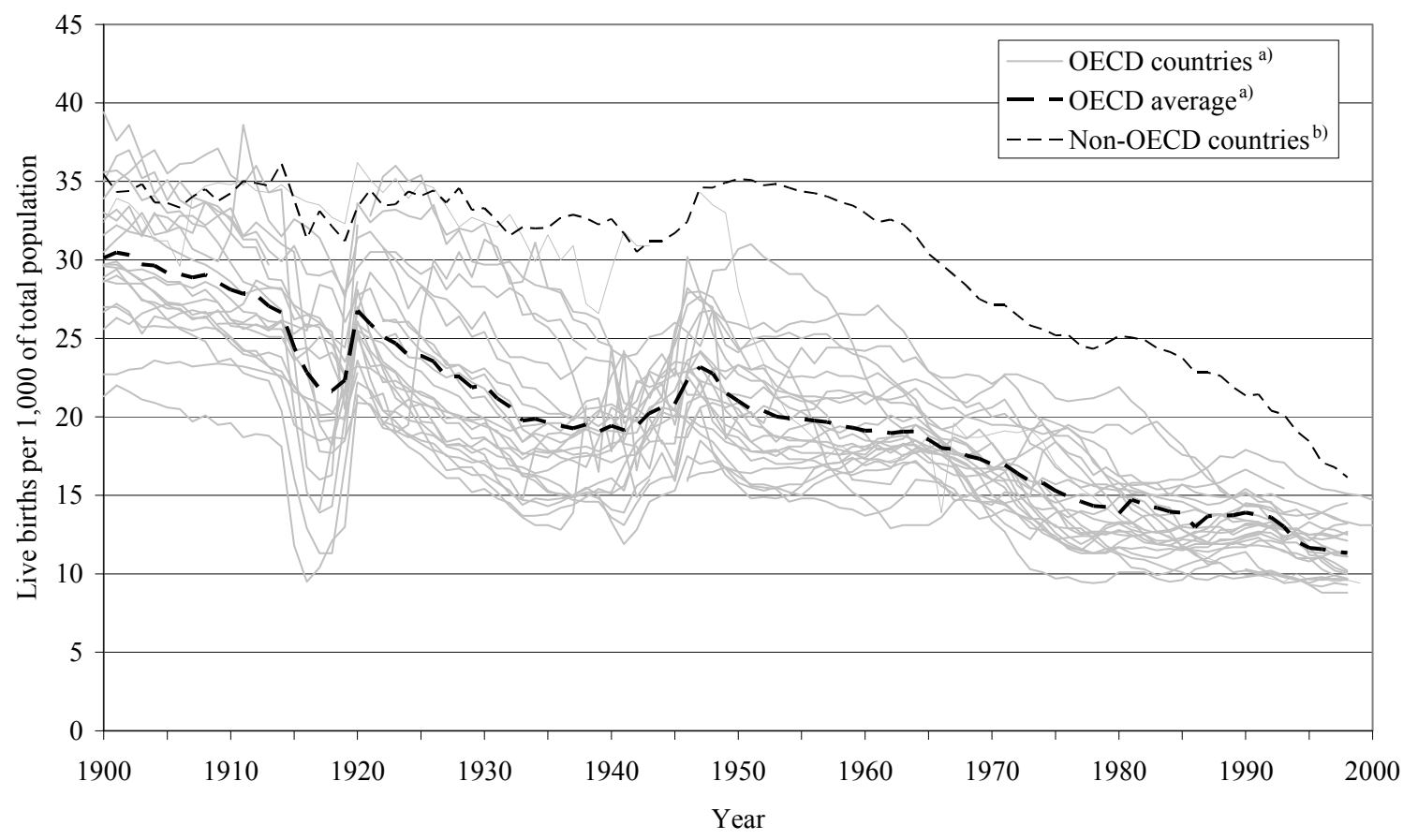

a) OECD countries covered in this figure are Australia, Austria, Belgium, Canada, Czech Republic (until 1991: Czechoslovakia), Denmark, Finland, France, Hungary, Germany (1949 to 1990: WestGermany), Greece, Ireland (until 1921: including Northern Ireland), Italy, Japan, Netherlands, NewZealand, Norway, Poland, Portugal, Spain, Sweden, Switzerland, United Kingdom (differentiated by England and Wales as well as Scotland) and the USA.

b) The Non-OECD average is calculated from data for Albania, Argentina, Barbados, Bulgaria, Chile, China, Columbia, Costa Rica, Cuba, Cyprus, Egypt, El Salvador, Fiji, Guadeloupe, Guatemala, Guyana, India, Israel, Jamaica, Malaysia, Martinique, Mauritius, Panama, Philippines, Puerto Rico, Rumania, Russia, Singapore, South-Africa, Sri Lanka, Taiwan, Trinidad and Tobago, Tunisia, Uruguay, Venezuela, Yugoslavia (until 1918: Serbia) and Zimbabwe.

Source: Mitchell (2003).

Another fertility measure which builds on the number of births occurring in a given year and normalizes it with respect to the population structure in terms of gender (concentrating on women) and age (taking age 15-44 or 15-49 to be the relevant age brackets) is the "total fertility rate" (TFR). It gives the number of live births a woman would have over her entire life cycle if, in each year of her fertile period of life, she had as many children as all women of the same age have had in a given year and country. The TFR is thus much closer to measuring actual fertility behavior than the CBR. Also, it provides a yardstick for the benchmark level of replacement fertility which, depending on national conditions regarding child mortality, is now about 2.1 (children per mother) in most developed countries. However, as it is based on cross-section data for a given year, the TFR can be distorted by short-term effects as well as by long-term changes which affect the average timing of births but need not alter the final number of children 
that real-world women have over the course of their entire life-cycle. A longitudinal measure which indicates precisely this is the "completed" or "cohort fertility rate" (CFR) which gives the number of live births an average woman from a particular age cohort has had over her entire life cycle. Therefore, the CFR is a genuine behavioral measure, a major drawback being that it can only be computed ex post for women who have (almost) completed their fertile period of life, being aged 44 or 49 , and fails to indicate on-going changes in fertility behavior of younger women.

Figure 2 shows current TFRs as well as the most recent results for CFRs in a number of OECD countries, using the latter to rank these countries from "high fertility" to "low fertility" - by the standards nowadays applying to developed countries. The figure confirms that fertility rates in many developed countries have indeed fallen substantially below the replacement level, certainly in terms of annual TFRs. A comparison with the latest results for the CFR reveals that, at least in a number of transition countries, this may be partly due to current economic conditions, while cohort fertility is still relatively high in most of these countries and its future course is open. In other countries, especially in Germany and Italy, not only current TFRs but also most recent CFRs are relatively low. There, as well as in Austria and Spain, each new generation is, and will be, smaller than that of their parents by between one fifths and one third, depending on whether current TFRs will adjust to the latest CFR figures in the long run or vice versa. Similar things are true for Japan, even though completed cohort fertility of women now aged in their mid-40s is still at an intermediate level there.

\subsection{The economic consequences - a case for public intervention?}

There is no a-priori reason why individuals should choose a reproductive behavior that exactly replaces their own generation in terms of size, nor does this benchmark have any particular appeal on normative grounds. Nevertheless, a population that is shrinking through low fertility, plus the resulting shifts in the age structure of the population which are reinforced through a continuous increase in life expectancy in most of the countries affected, may create a number of problems.

First of all, there is an obvious, negative impact on the prospects for financing payas-you-go schemes of social protection covering old-age pensions, health costs and the costs of long-term care. Problems of this kind are widely discussed in virtually all developed countries. In fact, they have already triggered far-reaching reforms in the generosity of such schemes in many places. Second, unless the participation rates of specific groups such as women, young people or older workers can be increased by substantial margins, projected reductions of the working-age population may imply considerable reductions in labor supply. As a consequence, the growth rates of GDP and, more 
Figure 2: Total fertility rates (2005) and cohort fertility rates (women born 1960-61) in OECD countries

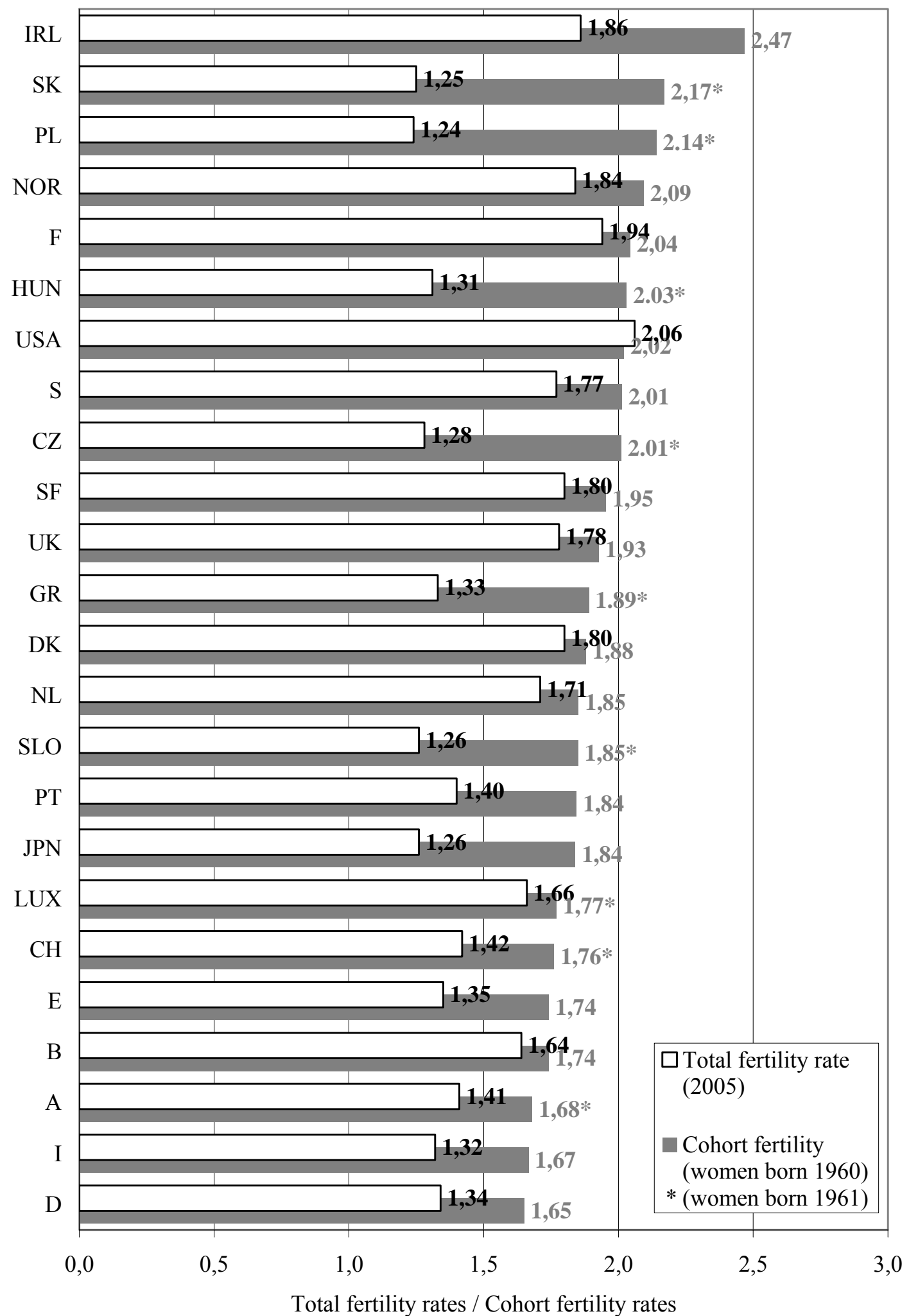

Source: Eurostat; national statistical offices. 
importantly, of GDP per capita must be expected to shrink even if GDP per worker, i.e., labor productivity, will continue to grow under the conditions of demographic change as it did in the past. These prospects for slower economic growth could be modified, albeit in different ways, through repercussions which are less well understood thus far. On the one hand, productivity growth could be accelerated through "capital deepening" if saving and investment remain high in industrialized countries with a shrinking labor force. On the other hand, investment may go down as well in response to declining rates of return, and the ageing of the labor force may in itself become an obstacle for continuous innovations as a source of productivity growth. ${ }^{3}$ The countries affected most seriously may thus be faced with some difficulties in maintaining their positions as relatively rich countries with high levels of human capital and strong technological progress when the fertility decline experienced in the past turns into overt demographic ageing.

Here, the most important question is whether, in themselves, these negative consequences of the fertility decline showing up at a macro level constitute a case for public intervention that targets fertility. Basically, the answer is no. If markets are functioning properly, and if individuals are feeling all the costs and benefits which result from their decisions, there are no reasons why they should be stopped from taking them. For instance, prospective difficulties in funding for their old age from the aggregate output of a slow-growth economy and under the resulting changes in relative factor prices if they have fewer children are simply a specific type of costs they should have taken into account when making their relevant choices. That these costs are potentially huge when looked at more closely does not change this assessment fundamentally from an economist's point of view. ${ }^{4}$ What deserves a second look, however, is whether markets and all the other institutions involved are actually working, that is, whether there aren't any potential distortions in how individuals are making their fertility decisions in the first place. In other words, one has to understand the micro-level reasons for the fertility decline and to ask whether something may be wrong about these.

\section{Family Economics: Main Mechanisms That May Reduce Fertility}

Individual fertility behavior is influenced by a host of factors which may not all be equally accessible for an economic analysis. Nevertheless, the economics of the family which was basically inaugurated through the contribution by Becker (1960) offers four

\footnotetext{
3 Theory alone is not enough to settle the controversies about these points. The relevant evidence is limited but does not seem to be very encouraging (see, e.g., Lindh and Malmberg 1999; Feyrer 2007; or Werding 2007).

4 The only aspect just mentioned that may call for a different conclusion is the potential growth externality of a shrinking and ageing labor force. But the ground to make this a strong argument is shaky.
} 
major potential explanations as to why fertility has continued to decline in most developed countries since the middle of the $20^{\text {th }}$ century (see Hotz et al. 1997 for a survey). ${ }^{5}$

- A quantity-quality interaction triggered by a particular structure of parental preferences regarding children (Becker and Lewis 1973);

- Increasing opportunity costs, especially for potential mothers, caused by changes in women's preferences that influence the household time allocation (Willis 1973);

- Changes in the bargaining situation of partners that have an impact on a broader class of household-level decisions (Pollak 1985; Ott 1992);

- Fiscal externalities of bringing up children caused by large-scale public interventions in the field of intergenerational distribution (Cigno 1986; 1993).

Note that these differing explanations are by no means mutually exclusive. Rather, they may interact and reinforce each other.

\subsection{Becker's quantity-quality interaction}

The interaction between "child quality" and the number of children which was first suggested by Becker (1960) and fully worked out in Becker and Lewis (1973) was meant to reconcile the Malthusian idea that increases in income tend to stimulate fertility with the observation that income growth has been accompanied by a secular decline in fertility (see Willis 1973). Becker rejects any explanations which take children to be inferior goods. Instead, he argues that the puzzle could be resolved within a model of stable parental preferences by which children are normal or even superior goods and have a constant price per unit of "child services" if one acknowledges that the demand for children effectively involves, in addition to the quantitative dimension represented by the number of children $n$, a qualitative dimension $q$ associated with the choice of expenditure per child. As a result of this sub-distinction, Becker gives a conclusive explanation by which high-income families may end up having lower fertility simply because they face higher effective prices of children along the quantitative dimension.

In his model ${ }^{6}$ parents maximize a utility function $u=u(n, q, s)$, where $s$ denotes the parents' standard of living. The household's budget is given by $I=p_{c} n q+p_{s} s$, where $I$ denotes total family income, $p_{c}$ the price of goods and services devoted to "child services" $c \equiv n q$ and $p_{s}$ the price of goods and services consumed by adults. When

\footnotetext{
For the earlier period of fertility decline (see Section 2), tremendous reductions in child mortality appear to be important which could also be incorporated in economic models using "children who survive until adulthood" as the parents' core objective. In addition, a breakdown in habits and norms in place in agricultural societies may play a role (see Birg 1995), which has some bearing on the following explanations.

6 The following summary draws on Hotz et al. (1997) as well as on Werding (1998, section 2.2).
} 
Figure 3: Interaction of the demand for quantity and quality of children

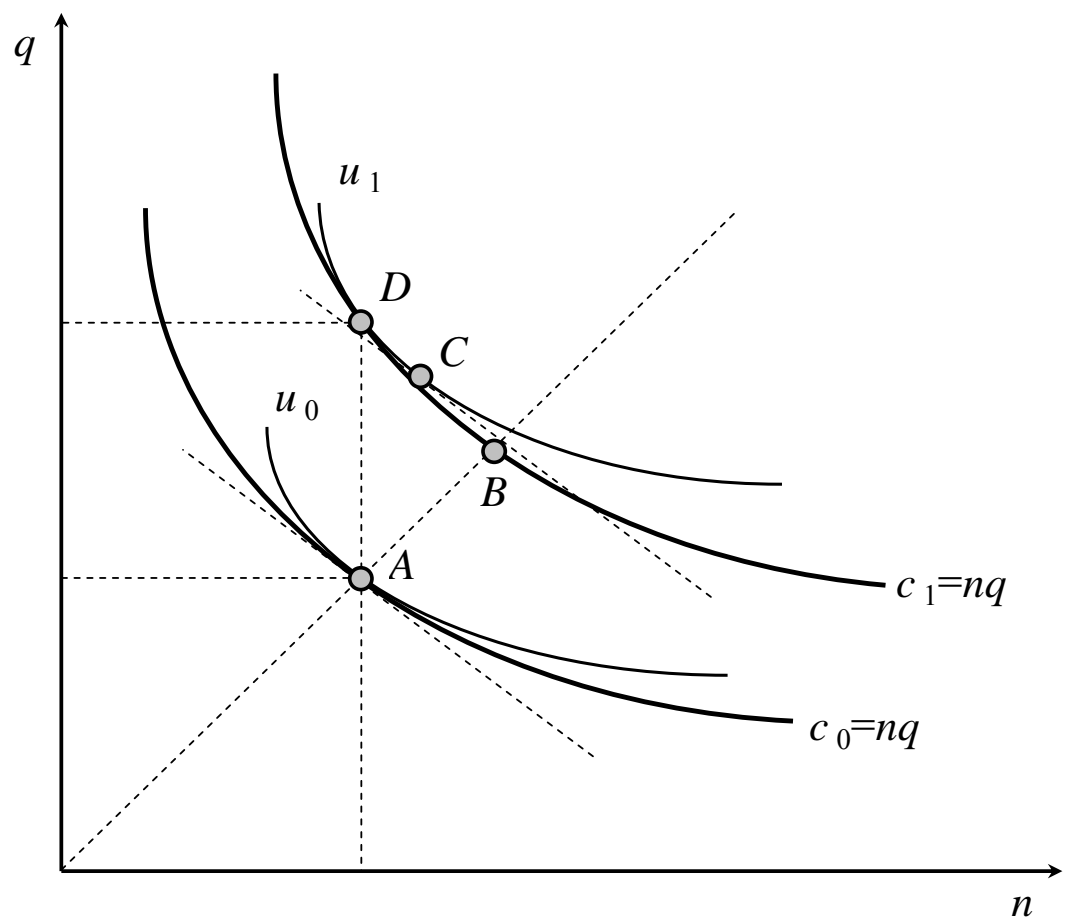

Source: after Hotz et al. (1997).

choosing the optimal use of $I$, parents thus have to balance utility drawn from consuming $c$ and $s$, and they must also decide whether to spend money on $n$ by having another child or on $q$ by increasing the quality of a given number of children. The most important thing to note is that, under this assumption, the parent's budget constraint becomes non-linear because the quantity and quality of children enter multiplicatively.

A direct implication of the model is that the income elasticities of demand for $n, q$ and $s$ must satisfy the relationship $\alpha \varepsilon_{C}+(1-\alpha) \varepsilon_{s}=1$, with $\varepsilon_{C}=\varepsilon_{n}+\varepsilon_{q}$, where the $\varepsilon$ 's denote the relevant income elasticities, and $\alpha$ is the share of family income spent on children. Assuming that children are normal goods in the sense that total expenditure on children is an increasing function of income, the sum of the income elasticities of the number and quality of children must be positive $\left(\varepsilon_{n}+\varepsilon_{q}>0\right)$. But it is possible that the observable income elasticity of demand for additional children is negative $\left(\varepsilon_{n}<0\right)$ if the income elasticity of quality is large enough.

The parents' optimal choice regarding the number and quality of children is illustrated in Figure 3. An initial equilibrium is represented by point $A$. Here, the indifference curve $u_{0}$ is tangent to the budget constraint, $c_{0}=n q=\left(I-p_{s} s\right) / p_{c}$, where $c_{0}$ is the household's real expenditure on children and $s=s\left(p_{c}, p_{s}, I\right)$ is demand for the parents' standard of living. Point $A$ is an interior solution, i.e., it corresponds to maxi- 
mum utility, if the indifference curve is more concave than the budget constraint, the latter being given by a rectangular hyperbola. Thus, quality and quantity should not be too closely substitutable in parental preferences if the second-order conditions for utility maximization are to be satisfied. The non-linearity of the budget constraint then causes a quality-quantity interaction as income increases. Specifically, it leads an endogenous substitution effect away from the number of children and in favor of child quality if the income elasticity of demand for $q$ exceeds the income elasticity of demand for $n$. To see this, note that in this model the marginal rate of substitution between the quantity and quality of children is $u_{n} / u_{q}=\pi_{n} / \pi_{q}=q / n$; here, $u_{n}$ and $u_{q}$ are marginal utilities and $\pi_{n}$ and $\pi_{q}$ are marginal costs, or shadow prices, of $n$ and $q$ which are endogenous and mutually depend on $q$ respectively $n$. As a result, the relative cost of the number of children tends to increase as the ratio of quality to quantity increases with income $I$, which it will if $\varepsilon_{q}>\varepsilon_{n}$.

If, for instance, higher income induces the household to increase demand for children from $c_{0}$ to $c_{1}$, the parents' relative preferences regarding $n$ and $q$ imply that the new equilibrium is to the left of point $B$ (with a constant $n$-to- $q$ ratio) at point $D$. If the relative costs of $n$ and $q$ were unchanged, the new equilibrium, located on the indifference curve, $u_{1}$, would be at $C$ rather than $D$, with lower $q$ and higher $n$. The total effect of an increase in household income can thus be decomposed into a pure "income effect", holding $\pi_{n} / \pi_{q}$ constant, from point $A$ to point $C$, and a "substitution effect" from point $C$ to $D$. In Figure 3, the increase in income leaves the number of children unchanged because the income effect which increases desired fertility is exactly off-set by the substitution effect which is induced by increased expenditure per child associated with higher desired quality. Depending on the precise structure of parental preferences for $n$ and $q$, even a reduction of the number of children is possible.

Furthermore, Becker and Lewis (1973) show that the elasticity of demand for the number of children is likely to be more negative with respect to variables affecting $p_{n}$ (e.g., contraception or maternity costs) than it is with respect to variables affecting $p_{c}$ in total. On the other hand, a decrease in $p_{q}$ (e.g., through parents' education, quality of neighborhood, school quality and cultural factors) may have a negative effect on fertility as the direct substitution effect in favor of $q$ causes an increase in $\pi_{n}$.

\subsection{Time allocation and opportunity cost}

A negative relationship between household income and fertility can also be explained by the observation that higher household income is often associated with a higher cost of female time, either because of increased female wage rates or because higher income raises the value of female time in non-market activities. In any case, if child-rearing is a 
relatively time-intensive activity, especially for mothers, the opportunity cost of childrearing tends to increase relative to sources of satisfaction not related to children, which again leads to a substitution effect away from having children. Note that, to the extent that this substitution effect is triggered by higher female wages, there must be another, more fundamental explanation, for instance, through a change in women's preferences vis-à-vis the options of participating in the labor market vs. taking care of children, or through changes in the way males and females interact with each other when forming a household and making household-level decisions. ${ }^{7}$

A simple framework for studying the link between time allocation, labor supply and fertility behavior was suggested by Willis $(1973)^{8}$ based on a utility function for household-level decisions that can be captured by $u=u(n q, s) .{ }^{9}$ Following Becker (1965), he assumes that basic commodities, such as satisfaction from children and adult standard of living, cannot be purchased directly in the market. Instead, non-market time of household members and purchased goods are used as inputs into household production the outputs of which enter the utility function. For simplicity, it is further assumed that only the wife is active in household production, while the husband fully specializes in market work and his income, $H$, can be treated as exogenous. Total household income is $I=H+w L$, where $w$ is the wife's real wage and $L$ is labor she supplies to the market. Satisfaction from having children is again measured by "child services" $c=n q$.

Household production is assumed to have constant returns, the production functions being $s=g\left(t_{s}, x_{s}\right)$ and $c=f\left(t_{c}, x_{C}\right) ; t_{s}$ and $t_{c}$ are the wife's time inputs and $x_{s}$ and $x_{t}$ are marketable goods devoted to the production of adult standard of living and child services, respectively. A key assumption of the model is that the production of $c$ is more time-intensive than the technology for producing $s$. The wife's total time is allocated to home production and market work, that is, $T=t_{c}+t_{s}+L$. Similarly, purchases of market goods are constrained by total household income, so that $I=H+w L=x_{C}+x_{S}$.

In Figure 4, the production possibility frontier of the household, illustrated by the curve $S^{\prime} C^{\prime}$, indicates the corresponding outputs of $c$ and $s$. The (absolute value of the) slope of this curve is equal to the relative shadow price of children, $\pi_{C} / \pi_{s}$, and to the shadow price of the wife's time, $\hat{w}=f_{t} / f_{X}=g_{t} / g_{X}$, which both tend to increase as

7 In themselves, higher qualifications, higher wages and higher participation rates of women which are observable throughout the industrialized world are no exogenous determinants of fertility. Instead, they should be seen as the result of choices shaped by preferences which have shifted in this particular direction (Rosenzweig und Schultz 1985) or by the intra-household bargaining situation (Pollak 1985; Ott 1992, see Section 3.3).

8 The following sketch is based on Hotz et al. (1997).

9 To avoid formal complications involved in the quantity-quality interaction discussed in Becker and Lewis (1973), the product of the two dimensions, $c=n q$, can effectively be used as an argument in the parental utility function. 
Figure 4: Time allocation and fertility decisions

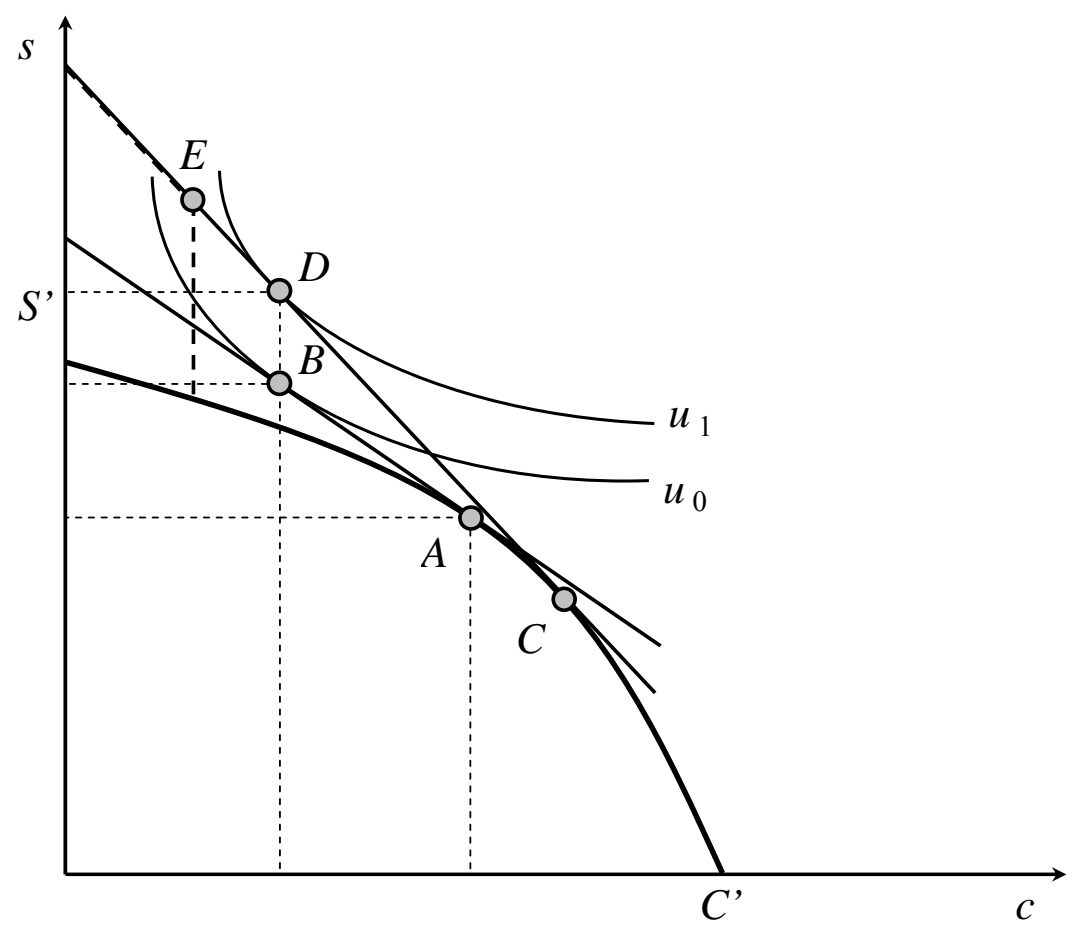

Source: after Hotz et al. (1997).

the output of children increases. Conversely, if the output of $s$ is increased, the shadow price of the wife's time will fall below the market wage, $w$, at some point, implying that it is inefficient for her to spend all of her time in household production. In the diagram, this is assumed to happen at point $A$. If the wife enters the labor market, thereby increasing household monetary income and decreasing the supply of non-market time, the shadow price of her time is increased and becomes equal to her market wage. Therefore, household output can be increased beyond the boundaries of the production frontier associated with full-time housework. This is illustrated by the ray which is tangent to point $A$ (which, in turn, is located on the production possibility frontier constraining the household when the wife does not participate in the labor market). The points on this ray lie outside the frontier, which illustrates the efficiency gain accruing to the household through adjustments in the wife's external labor supply.

Fertility is then determined by maximizing the utility function subject to the production possibility frontier and the option of working outside the household. In Figure 4, the optimum is given by the tangency point of the household's indifference curve and the linear segment of the augmented production frontier at $B$. Against this background, an increase in $w$ causes the point at which it is efficient for the wife to enter the labor market to shift from $A$ to $C$. The linear segment of the new, augmented frontier is both 
outside of, and steeper than, the linear segment of the old frontier. In other words, the increase in $w$ increases both the household's real income and the opportunity cost of having children. The effect for the production of child services is therefore ambiguous as the positive income effect in favor of $c$ can be (more than) offset by a substitution effect away from $c$. In the graph, an exogenous ${ }^{10}$ increase in $w$ causes the optimal choice to move from $B$ to $D$, leaving $c=n q$ exactly unchanged. Yet, even in this case, it is still possible that fertility in terms of $n$ decreases while child quality $q$ increases. Willis (1973) argues that this is likely to be the result because it seems implausible that child quality remains unchanged, while the parents' standard of living increases.

The effects of the wife's option to supply part of her time in the labor market and of changes in her wage rate are also affected by obstacles to freely adjusting the time spent on different uses. If, for instance, market jobs are available only with relatively fixed portions of time inputs (few hours - half-time - full time, probably with differing wage rates attached to any of these categories) or if institutional child care follows relatively rigid time schedules, the household's effective budget line can become kinked, as is indicated by the dashed line in Figure 4. If these rigidities become apparent only ex post, this will reduce the household's full income at given $c$. However, if they are expected ex ante, the household may choose an even smaller level of child services and fertility than with the opportunity to reallocate the wife's time smoothly, e.g., by choosing the solution at point $E$ under these additional constraints.

\subsection{Intra-household bargaining}

With the time-allocation approach, economists start taking a look at the internal structure of the family household. Nonetheless, the existence of the household is still taken as given, and the possibility of conflicts between the two partners is neglected in this view. This limitation is removed by Pollak (1985) who suggests a transaction-cost approach to analyzing the formation as well as the behavior of family households and in-

10 Of course, the wife's wage rate is not really exogenous. Instead, her life-time earnings capacity could be assumed to depend on the stock of her human capital at the outset of marriage, $h$, and on job experience which, in turn, is an increasing function of her life-time labor supply, $L$. Then, her lifetime earnings are given by $w(L, h) L$, where $w$ is her average life-time wage. Optimal time allocation requires the wife to adjust her life-time labor supply so as to equate the shadow price of her time, $\hat{w}$, to her marginal wage, $w^{\prime}=w+w_{L} L$. This implies that the price of her time tends to exceed the average wage and, more importantly, that it is effectively an endogenous variable. Also, an increase in the wife's initial stock of human capital, $h$, tends to increase her marginal wage rate, $w^{\prime}$, and, therefore, the opportunity cost of children, again causing a substitution effect against children. Unless her labor supply curve is backward bending, the increase in $h$ will tend to increase $L, w^{\prime}, I$ and $\pi_{c}$. If the positive wealth effect of $h$ does not offset the negative substitution effect, the desired level of child services, $c$, and with even higher probability the desired number of children, $n$, will decrease. 
tegrates concepts from bargaining theory into the analysis of household-level decisionmaking. ${ }^{11}$ The latter aspect was fully spelt out, and explicitly applied to parental fertility decisions, by Ott (1992).

To consider couples and families as cases of long-term interactions between rational individuals that are essentially based on incomplete, or implicit, contracts - reducing transaction costs and facilitating specific investments but giving rise to asymmetric risks of a dissolution of the contractual relationship - has direct implications for the economic analysis of fertility choices. In this view, families are basically seen as institutions for co-operative production, joint consumption and mutual insurance of its members, meant to organize and improve the life of individuals. Shifts in the balance of advantages and disadvantages of families vis-à-vis competing institutional arrangements, most prominently, the market and the state, may then serve as explanations for the "nuclearization" of the family and for the reduction of average family size during the processes of industrialization and modernization. Beyond this general conjecture, the analysis of intra-household bargaining can provide more specific answers as to why fertility is reduced as a rational response of individuals who no longer follow pre-defined, "traditional" role models in their interactions and who can no longer rely on an external stabilization of their partnership through relevant social norms. ${ }^{12}$

In a bargaining approach to marriage and fertility, child services $c$ are again seen as one of the most important commodities that are specifically produced and consumed within families (Ott 1992). ${ }^{13}$ Furthermore, fertility decisions are considered the outcome of a bargaining between two partners, one a male $(m)$ and the other a female $(f)$, which is basically held in accordance with the solution concepts of co-operative game theory but is constantly at risk of being played non-cooperatively if the co-operative solution cannot be made the subject of a complete and strictly binding contract. According to the "Nash rule" for co-operative games, the two partners are assumed to maximize a utility functional $\left(u^{m}-u_{0}^{m}\right)\left(u^{f}-u_{0}^{f}\right)$, where $u^{i}, i \in\{m, f\}$, are the partners' utilities in the case of an agreement and $u_{0}^{i}$ are their fallbacks, or "threat points", in the absence of an

11 To be sure, marriage decisions and potential conflicts within families were sometimes dealt with in the earlier literature, yet mainly with the ambition to show that the family household may still have a welldefined set of preferences and can be meaningfully considered "the" unit of analysis. Important predecessors for an innovative view are Ben-Porath (1980) for the transaction-cost perspective and Manser and Brown (1980) or McElroy and Horney (1981) for the application of bargaining theory.

12 At a micro-level, candidates for the underlying causes of these changes are again a change in women's preferences regarding labor-force participation vs. household production or a shift in individual expectations regarding the stability of marriage. Ultimately, it will be difficult to assess whether women were forced to become more active in the labor market because they or their husbands could consider a divorce, or whether divorce became an option because women were more economically independent.

13 This sketch draws on Werding (1998, section 2.3). 
Figure 5: Bargaining between potential parents

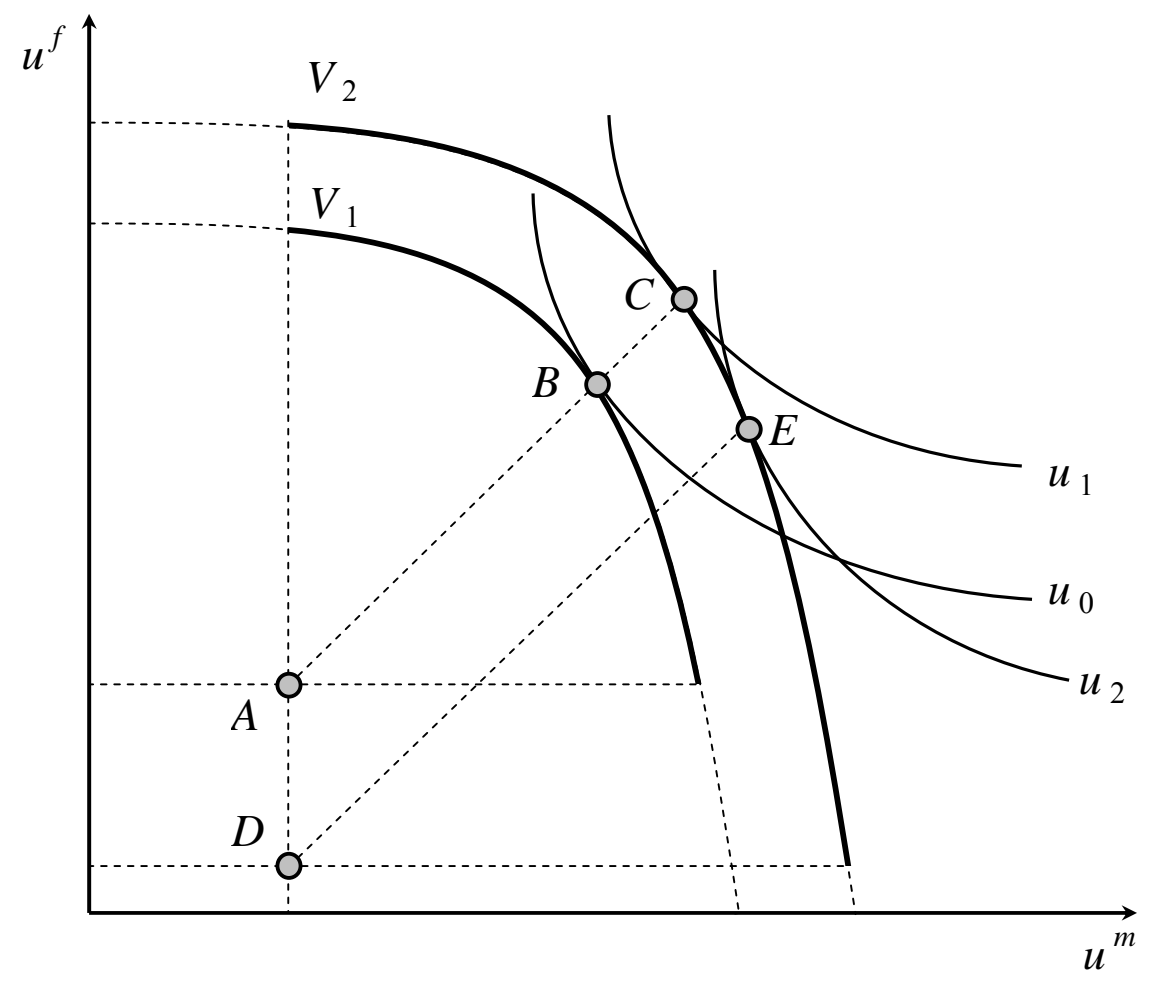

Source: after Werding (1998).

agreement or if the current agreement breaks down. An agreement is feasible if it leads to a utility frontier which lies outside the combination of the two threat points in the $\left(u^{m}, u^{f}\right)$-space, i.e., if it implies a potential utility gain for both of the partners.

Figure 5 illustrates the situation of a bargaining between the two partners about the number of their children (and probably also about the resources spent on child quality) assuming, once again, that the production of children (or child services) is relatively time-intensive. Forming a couple is attractive for the partners since, starting from a situation where both would be singles (and childless) at point $A$ with $\left(u_{0}^{m}, u_{0, \neg C}^{f}\right)$, it may lead them to point $B$ on the utility frontier $V_{1}$. Rearing children is also basically attractive as it may take the partners further to point $C$ on the utility frontier $V_{2}$. However, taking care of children (and spending time on increasing their quality) may have an impact on the outside option of the partner who mainly engages in these activities, in most cases the mother. The reason is that spells of non-participation or part-time work impede the accumulation of job experience and may even lead to de-qualification, which all reduces expected life-time earnings of the individual affected. As a consequence, the new combined "threat point" for a solution with children may be $D$, with $\left(u_{0}^{m}, u_{0, c}^{f}\right)$, instead of $A$. This, in turn, changes the final bargaining solution from $C$ to $E$ 
if the partners are unable to commit irrevocably to taking $A$ as the relevant "quasi-threat point" throughout. However, for the partner whose bargaining position is weakened through a decision in favor of children, solution $E$ is less attractive than $B$, that is, a continuation of the partnership without children. Starting from the initial situation at point $A$, the two partners may thus be unable to reach utility frontier $V_{2}$ which is "technically feasible", but instead end up being located on $V_{1}$ which is "rationally available".

To obtain results that are less extreme, the analysis can be easily adapted to a situation in which the alternative is to have a small number of children, allowing the caretaking partner to maintain a sufficient degree of labor-force attachment to keep up qualifications and job experience, vs. a higher number of children, which would definitely disrupt the care-taker's professional career. Also, the decision of whether or not to have children may simply be postponed, based on considerations such us those sketched above, until the two partners are able to assess the reliability of a long-term agreement between them. In fact, loyalty and reputation are the only means for an internal stabilization of the above bargaining situation. Still, this may reduce a given couple's final number of children, certainly if they run against the biological limits to child-bearing.

\subsection{Fiscal externalities}

Competition with alternative institutional arrangements was already mentioned in the last sub-section as a potential explanation for the reduction of average family size. Another economic explanation for the decline in fertility can therefore be derived from the idea that one of the principal motives for having children is old-age support (see already Leibenstein 1957), which makes children not only a consumption good from the perspective of their parents but also an investment good. Then, the continued fertility decline during the $20^{\text {th }}$ century may be related not only to the expansion of capital markets but also to that of publicly provided pension schemes which took place over this period. This so-called "social-security hypothesis" (Nugent 1985) was formalized and fully explored by Cigno (1993). ${ }^{14}$

14 In this and all of his subsequent work, Cigno (1993) uses a model with a sharp variant of this hypothesis taking children to be only investment goods which provide no direct satisfaction to their parents. At the same time, he assumes that agents are heterogeneous in that some are willing to comply with a "family constitution" prescribing a particular set of transfers between parents and children, while others are not. This constitution is "self-enforcing" for those whose internal rate of return from complying is sufficiently higher than the market rate of interest or the internal rate of return involved in the public pension scheme. In other words, the constitution may break down for some individuals through changes in the institutional set-up, but at an aggregate level there will still be a positive level of fertility as long as there are still some "compliers". See Cigno and Werding (2007, ch. 5) for a detailed discussion of this model. 
In a model that is close to the models sketched so far, ${ }^{15}$ individuals or, rather, households are assumed to live for three periods. Those born in period $t-1$ are economically active in $t$, then maximizing a utility function $u=u\left(s_{t}, s_{t+1}, q_{t} n_{t}\right) .{ }^{16}$ Since they earn wages only in the intermediate period of life, they have to pay for their children while these are young, the price for each "quality unit" of a child being $p$, and they have to reallocate consumption to the third period of life, i.e., old age. In the absence of capital markets and public pensions, such transfers can be brought about based on a self-enforcing set of family rules. The rules of this "family constitution" prescribe that those who are old in period $t+1$, in return for having incurred the usual cost of raising a child, $p q$, in $t$ will receive some fraction $b$ of their children's wage earnings in $t+1$ - provided that they have complied with the same rule one period before. Note that the marginal rates of return involved in this system may be a declining function of $q$ if the latter is interpreted as the children's human capital. ${ }^{17}$ The introduction of (wide-spread access to) capital markets can then limit the scope of the family constitution but need not make it disappear. A condition for the family constitution to survive in the presence of capital markets is that the marginal rate of return to investment in children, $\rho$, is higher than the interest rate, $r$, to make up for the transfer of $b w_{t}$ to the grandparents.

However, the introduction of a compulsory pay-as-you-go public pension scheme can make the family constitution collapse. Since those currently middle-aged have no choice but to pay contributions to the pension scheme and since they are promised a pension later on, irrespective of whether or not they support their parents and have children themselves, they may refuse to support the present old and they will have children and spend resources on child quality only because of their consumption motive for fertility. Even if the pension scheme offers a marginal rate of return lower than $\rho$ (and higher, equal to or lower than $r$ ), the intra-family arrangement may no longer be attractive because of the transfer of $b w_{t}$ to the (grand-)parents involved. Yet, while this response is a reasonable strategy from a purely private point of view, it is harmful for society at large because the public pension scheme is also based on children and human capital, just like the family constitution.

After the introduction of the public pension scheme, with a contribution rate $\tau$ and period- $t+1$ benefits $\beta_{t+1}$, the household's intertemporal budget constraint is given by $s_{t}+p q_{t} n_{t}+s_{t+1} /\left(1+r_{t+1}\right)=(1-\tau) w_{t}+\beta_{t+1} /\left(1+r_{t+1}\right)$. Maximizing utility subject to

15 This summary draws on Werding (1998, section 5.3).

16 The quantity-quality interaction may well become untractable in the present, inter-temporal context. Therefore, total "child services" $c=n q$ are again used as an argument in the parental utility function.

17 This introduces a slight equivocation into the model because Becker's "child quality" as perceived by the parents is not necessarily the same as qualifications of a child that can be used productively. However, a more careful distinction would not make a difference of first-order significance. 
Figure 6: Fertility under a pay-as-you-go public pension scheme

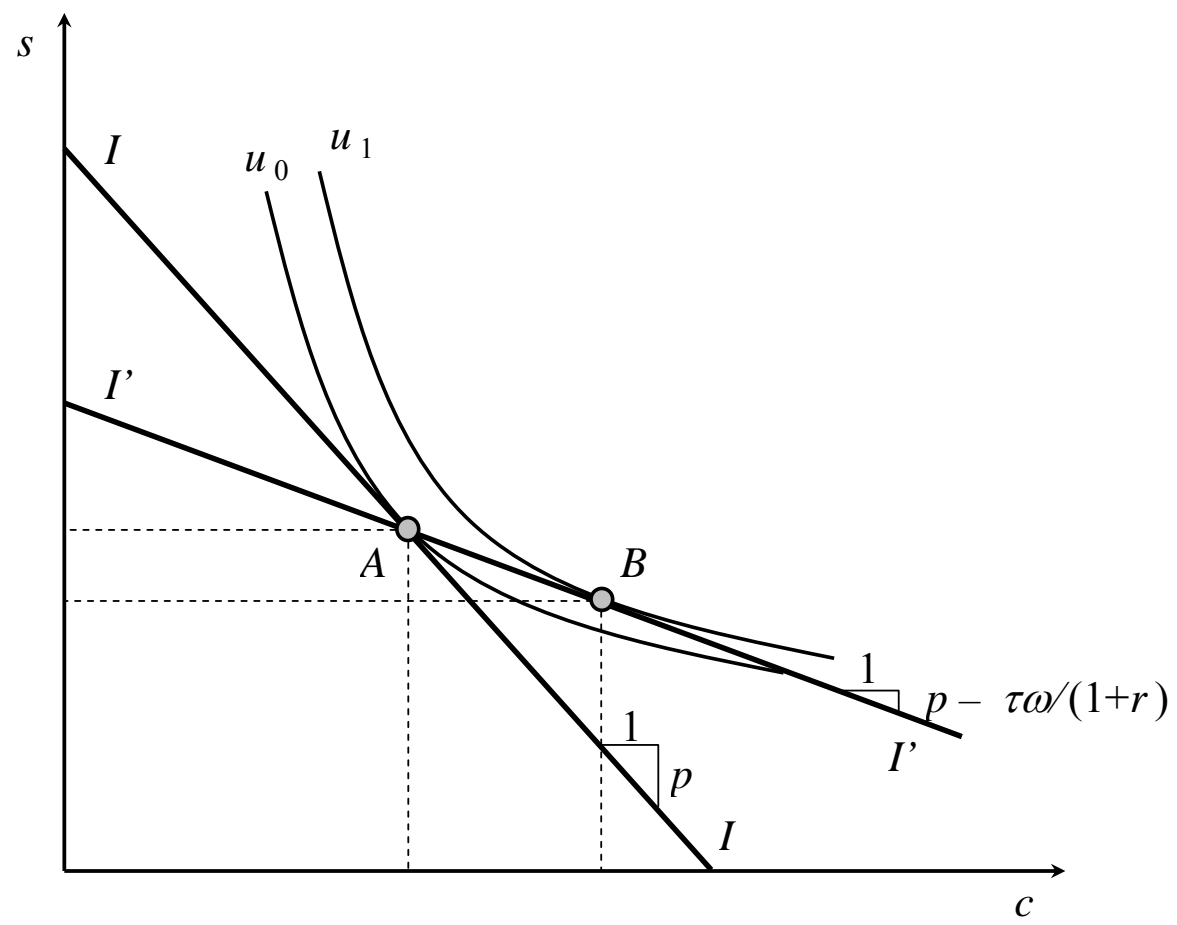

Source: after Werding (1998).

this constraint yields a substitution rate between goods consumption in periods $t$ and $t+1, u_{s, t} / u_{s, t+1}=1+r_{t+1}$, which governs saving decisions, and a substitution rate between period- $t$ consumption and child-related expenditure, $u_{s, t} / u_{c}=1 / p$, which is relevant for the household's fertility choice. Since pension benefits are usually lumpsum (in a Beveridgean pension scheme), or linked to earlier contributions and wages (in a Bismarckian scheme), they do not preserve the parental investment motive for fertility. With respect to public pension that are financed on a pay-as-you-go basis, however, raising children is still an investment - in fact, the only one which really funds each generation's old-age pension. If all households are identical, benefits $\beta_{t+1}$ are effectively equal to $\tau w_{t+1} n_{t}$ by the pension scheme's periodic budget constraint. If individuals would respond to this identity, they would choose a higher level of child services until $u_{s, t} / u_{c}=1 /\left(p-\tau \omega_{t+1} /\left(1+r_{t+1}\right)\right)$, where $\omega$ is the wage rate per efficiency unit of labor (assuming, for simplicity, that the impact of $q$ on $w$ is linear, with $w_{t+1}=\omega_{t+1} q_{t}$ ). Note that, under the "family constitution", a parallel condition would hold, only with the transfer rate $b$ in the place of the contribution rate $\tau$. In other words, the public pension scheme replaces the old family system, but fails to replicate its incentive structure.

Here, the reason for the reduction in fertility and expenditure on children is a "fiscal externality" which is created by the way pension benefits are usually assessed (Werding 
1998; Sinn 2000; 2001). The value of children as an investment good is socialized by these schemes, and the returns are redistributed to all members of the parents' generation so that they become immaterial for individual fertility choices. Even if all households choose the same amount of $c$ because of the utility directly derived from doing so, the externality leads to a symmetric equilibrium in which aggregate-level fertility is too low from a social point of view, with a negative impact on life-time utility of each household. This is shown in Figure 6 which illustrates the choice of an average household between goods consumption over the life cycle, $s=s_{t}+s_{t+1} /\left(1+r_{t+1}\right)$, and child services, $c=q_{t} n_{t}$. Budget line $I I$, with a slope $p^{-1}$, and the indifference curve $u_{0}$ lead to the household-level optimum with a public pension scheme at point $A$. Since consuming this bundle would also be feasible if the externality highlighted above were internalized, budget line I'I' goes through this point but, with slope $\left(p-\tau \omega /\left(1+r_{t+1}\right)\right)^{-1}$, is less steep than line II. Under standard assumptions regarding the shape of the utility function, this implies that the utility level $u_{1}$ attainable at point $B$ must exceed $u_{0}$.

Thus far, uncertainty has not been mentioned in this review as a specific feature of fertility decisions which may deserve attention from a policy-oriented point of view. In fact, the outcome of actions that parents could possibly take to influence the quantity as well as the quality of their children (see Section 3.1) is subject to numerous risks. But this in itself does not call for public intervention. The reasons why potential parents, especially women, may seek a new balance between child-care responsibilities and labor-force participation (see Section 3.2), or why they may be careful about changing their intra-household bargaining position (see Section 3.3) may also be related to uncertainties of different kinds. Up to a point, the sheer duration of child-related commitments vis-à-vis those resulting from other choices may create an obstacle for risk-averse individuals to have (higher numbers) of children. Some kind of insurance of childrelated risks might thus be desirable, but it is difficult to see what exactly should be the subject of arrangements of this kind - beyond the provision of legal rules for the case of divorce or the maintenance of social infrastructure that creates a reliable framework for any form of life-cycle planning. However, things are different with respect to the issues discussed in the current section. In the context of intra-family arrangements of old-age support, uncertainty regarding the quantity and quality of one's children, plus uncertainty regarding the children's willingness to comply with such schemes, are clearly important. Here, offering insurance by pooling these risks and adding some degree of compulsion with respect to participation of the young are straightforward tasks that may effectively justify government intervention in the form of public pension schemes. At the same time, this insurance should never be designed in such a way that it removes all incentives for potential parents to invest in the quantity and quality of children as a 
means of self-insurance. The entire discussion in this section could therefore be restated in terms of an enormous moral-hazard problem, triggered by an inadequate way of insuring individuals against the risks associated with returns to investment in their children. Dealing with the various sources of uncertainty involved may then indeed have an impact on the design of better solutions, but it does not lead to a fundamental reassessment of the role of public pensions for parental fertility choices.

Last but not least, it should be noted that the story developed here for the case of public unfunded pension schemes may also apply to other types of government expenditure involving a considerable amount of intergenerational redistribution, such as public health-care and public schemes of long-term care insurance. To the extent that these programs are unfunded and, for those who are currently economically active, have to be financed by their children later on, they create a similar fiscal externality if the benefits are not linked in any way to individual investment in children or their quality.

\section{Policy Implications}

In the preceding section, four differing explanations for the continued fertility decline in developed countries were reviewed that emerge from the economic theory of the family. They can be derived using standard techniques for analyzing household-level decisions that are economically rational and each appear to be plausible. Whether they are also empirically valid, is still a different matter. But to the extent that they can be tested at all, which is difficult with respect to Becker's quantity-quality interaction, they are also supported by empirical work. ${ }^{18}$

The question that will now be addressed is whether, from an economist's point of view, these explanations have any policy implications, that is, whether they point to any kinds of market failure, failure of other institutions or any other deficiencies in the decision-making and in the interaction of the individuals involved, and whether these problems, provided they exist, could be cured through public interventions. The bottom line is that the first three explanations must be basically seen as rational adaptations of parents, especially mothers, to a changing environment, while the fourth one openly points to a potential source of inefficiency. At closer scrutiny, the second and the third ap-

18 Some readers may have missed any mention of advances in the technology of contraception in this survey of potential reasons for the fertility decline in developed countries since the 1950s. In the sense that oral contraceptives have made it easier to limit one's actual number of children to the desired one, they may indeed have contributed to the reduction in fertility - as is confirmed in some, but not all, empirical studies. Note, however, that these changes mainly affect the "production" of children, not so much parental demand for them. They are thus no integral part of any of the explanations sketched in Section 3 and, neglecting any ethical issues which might be involved, an economist would not find anything wrong about their impact. 
proach to explaining the fertility decline may also raise some concerns. From a welfarist perspective, the actual size of opportunity costs of taking care of children arising at the individual level could be considered "too high" under some conditions. Also, there could be measures that are suited to limit changes in the bargaining situation of a couple resulting from child-rearing activities of one partner. However, only with respect to the fiscal externality involved in bringing up children taking action is clearly required to reduce an obvious distortion of parental fertility decisions. In this case, it is by the way a sub-optimal type of policy intervention that gives rise to the problem in the first place.

The discussion of potential rationales for public intervention into parental fertility choices also leads to questions regarding policy measures that appear to be appropriate in each instant, at least in terms of broad categories of relevant instruments. Both these issues will therefore be discussed in this section in turn.

\subsection{Rationales for public intervention}

Before going on to discuss potential reasons for public intervention that arise from the economic theory of the family, hence mainly from efficiency considerations, some remarks on the role of equity considerations in the specific field covered here may be appropriate. Justifying interventions in individual fertility decisions by distributive goals can either mean that poor people are thought to have a right to have children even they cannot afford to raise them, or it could mean that people with low wealth and income should be prevented from having many children because this would make them poor, or poorer, in terms of resources that are available to their family on a per-capita basis.

By professional wisdom, economists have nothing to say on the first interpretation, as it is simply a normative statement. Note that the statement cannot be re-phrased in terms of a right of children to be born, even if their parents are poor. Once a child is born, however, the situation changes. Children are not only consumption goods or investment goods from the perspective of their parents. They are also new individuals, and a civilized society may find it appropriate to support them if they cannot do so themselves and if nobody else can. Of course, such a policy feeds back on parental fertility decisions, relaxing the budget constraint for those at the bottom of the income distribution who want to have children. Nevertheless, policies of this kind are pursued in most developed countries through measures such as income support, social assistance, etc. This may be taken to indicate that society is willing to accept the resulting incentive effects as an unavoidable distortion caused by an appropriate amount of redistribution. But it does not imply that the incentive effects are desirable in themselves. ${ }^{19}$

19 Note that this remark about distributive aspects of fertility choices could also be framed in terms of credit constraints for potential parents. To the extent that parents would be able to pay off monetary 
The alternative interpretation by which people close to, or in, poverty should be stopped from having children has several layers. If the point is that these people have children not by deliberate decisions, but as a by-product of other activities, giving them information about, and access to, contraceptive methods in order to help them avoiding unexpected, high costs might be defendable. It is an important side measure if these costs are effectively not falling on the individuals themselves who are acting irrationally, but if society is prepared to take them on. But if individuals are rational and follow a direct motive to have children, maintaining this interpretation becomes difficult. Note that, in this case, per-capita income and even total household income are becoming endogenous variables, so that they are poor indicators of a need for intervention. Those who are not satisfied with this assessment, for instance, because they are thinking about the situation in many developing countries where population is still growing fast and where this creates economic and social pressure, should think about the following. In most of these cases, there will also be efficiency reasons for why, and how, public intervention might be called for - above all an incomplete system of markets and other institutions, such as: limited access to financial markets; limited opportunities for women to become educated and to participate in the labor market if they wish to do so; limited opportunities for children (once they exist) to invest in their human capital so as to maximize their life-time income, etc. To the extent that these deficiencies can be addressed by public policy, this will also have an impact on the distributive side.

That said, it is time to turn to the differing approaches to explaining the decline in fertility and to ask in some more detail for their policy implications. The first approach, i.e., the quality-quantity interaction first suggested by Becker (1960), definitely provides no case for policy intervention. It is an elegant theory of how potential parents are making fertility choices which cannot be validated empirically because one of its key variables, the price of a unit of child quality, cannot be observed. The core mechanism that may lead to a reduction in fertility as household income increases is entirely based on the structure of parental preferences, which are beyond the scope of economic assessment. If parents are inclined to rank the "quality" of their children higher than the number of children they have, there is thus no reason whatsoever to criticize this on normative grounds.

Things are slightly different with regard to the second approach formalized by Willis (1973), by which the decline in fertility is explained through an increase in opportu-

child costs later on which they are unable to cover at once, giving them access to some type of loan arrangement through public intervention might be defendable. Otherwise, their budget constraint were effectively removed through fertility-related transfers, and they would tend to have "too many" children. For a related result see Baland and Robinson (2000). However, once a child is born, addressing the credit constraints it is faced with may well be a meaningful task. 
nity costs of child-rearing. Again, the core mechanism rests on simple conditions for an optimal time use (and, more profoundly, on changes in preferences or changes in the division of labor between two partners within a household) and is nothing but a rational response of potential parents to the economic conditions they are faced with. However, it was already mentioned that decisions regarding labor-force participation vs. home production and child care taken at the micro level could be constrained in such a way that the opportunity costs are higher than is necessary. This could be concluded, for instance, if there are rigidities with respect to the choice of an individual's working time or the availability of child-care facilities. ${ }^{20}$

To the extent that the opportunity-cost approach is capturing an unavoidable tradeoff, which it certainly does for any single household by its time constraint, there should be a negative relationship between fertility and (dominantly, female) labor-force participation at an aggregate level. Such a relationship has been observed across developed countries in the past, but more recently it has disappeared or was even seemingly turned over, as Figure 7 shows based on rough indicators. ${ }^{21}$ Apps and Rees (2004) take this observation to indicate that there are different ways of "framing" the choice between having (more) children or working (longer hours) in the labor market. ${ }^{22}$ Therefore, women living in different countries may effectively find themselves located on different "budget lines" (as those tentatively introduced in the above graph). In particular, flexibility with regard to the duration and disposition of working hours as well as availability and flexibility of child-care arrangements can do a lot to mitigate existing conflicts. Employers as well as public bodies could therefore provide some support in finding a better balance between the different options for using time productively.

It is difficult for a state to influence decisions taken by employers. Appropriate means of information and persuasion may be weak in their effects. Going further in the direction of regulating these decisions, through protective laws regarding equal opportunities for women or, more specifically, employees' choices of working hours may in fact produce adverse results if they are perceived by employers as increasing the expected costs of hiring those who should be protected. Key activities of the state in this context could therefore be related to the availability (and probably also the affordability)

20 Also, a stronger bargaining position of partners who take care of children, or a more equal (i.e., less traditional) burden sharing within the household with respect to activities of household production could shift "the" household's preferences in a different direction; see below.

21 Keep in mind that the total fertility rate is normalized with respect to actual age structure of women (see Section 2), while the female participation rate is not. In addition, the range of ages spanned by the female participation rate appears to be rather broad for the suggestive combination with the fertility rate. Also, there is no distinction here between full-time and part-time work. Still, more refined indicators would not yield a picture that is substantially different.

22 See Kögel (2004) for an empirical investigation that largely confirms this idea. 
Figure 7: Fertility vs. female labor-force participation in OECD countries, 2003

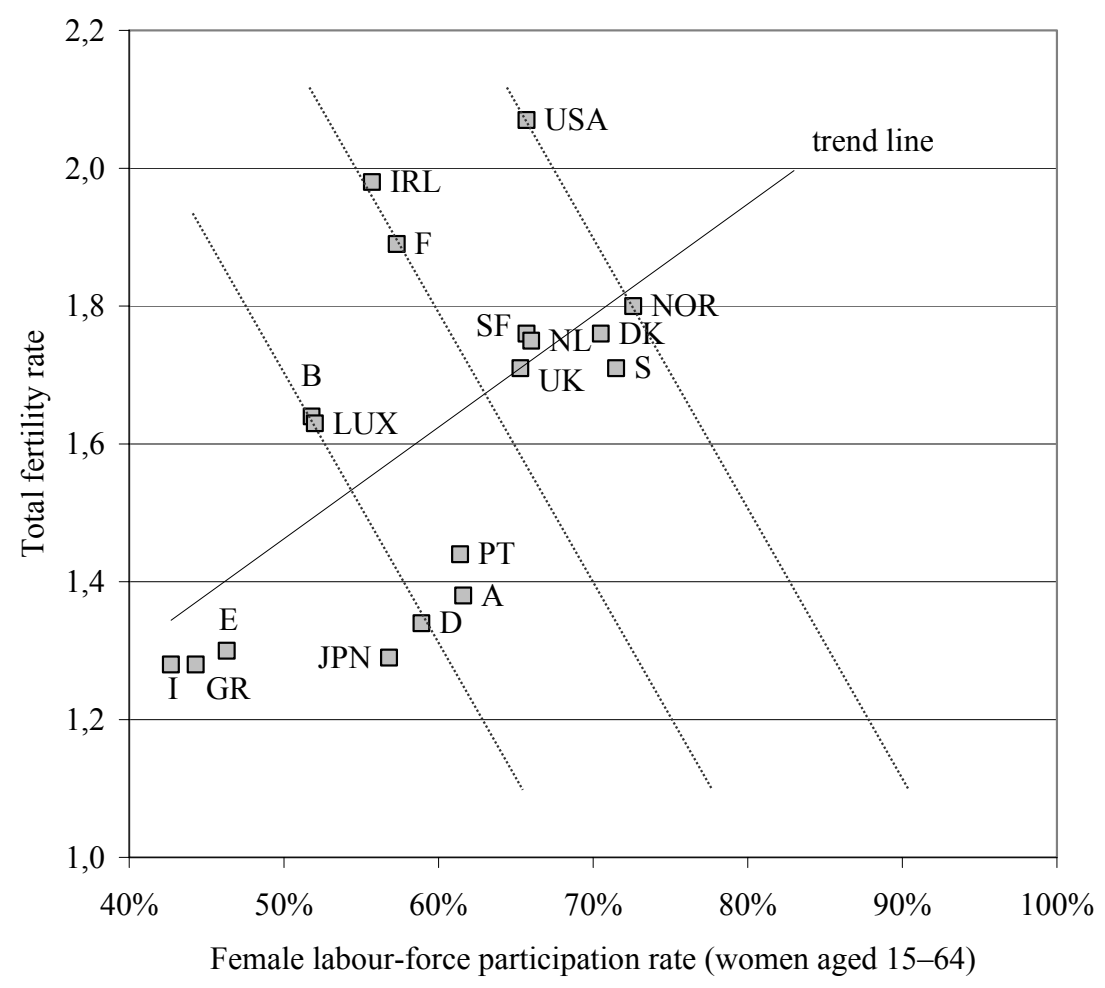

Sources: Eurostat; OECD; national statistical offices.

of child care. In particular, if public authorities take measures to ensure the quality of child-care facilities, ${ }^{23}$ they are soon in a position to be responsible for making arrangements for a quantitatively sufficient supply of such institutions. This does not necessarily mean that this has to be done via public provision, nor does it imply that the government has to take on all the costs involved. Some degree of a subsidization of child care may however be justified.

Difficulties of (married) couples to interact with each other when making fertility choices, as those captured in the bargaining approach suggested by Pollak (1985) and Ott (1992), raise similar policy issues as the opportunity-cost story just covered. Once more, there is nothing much to criticize about the basic rationality of responses to a perceived reduction in the reliability of partnerships and traditional role models which may have limited the need for individual-level bargaining in former times. However, poten-

23 This could be required by information asymmetries regarding the quality of child-care institutions: parents are purchasers but not consumers of their services, and small children may be unable to assess the quality and to communicate their assessment in a reliable fashion. Also, parents and children can rarely make comparisons across a larger number of facilities. Supporting parents in the socialization and early education of children by external institutions may also be considered desirable for distributive reasons, with an eye on the situation and prospects of the children. 
tial conflicts and, in particular, the change in bargaining positions that is typically related to child-care responsibilities of one partner can again be reduced through a number of policy measures. Like in the opportunity-cost approach, public intervention which improves the opportunities to combine labor-force participation with child-rearing activities could prove effective in doing so. In addition to that, a number of public regulations, for instance, regarding mutual obligations of two partners within an on-going marriage and, more importantly, in the case of divorce, could be used to modify changes in each partners' bargaining power. However, the scope for policies of this latter type is limited in two ways. First, they may have an adverse impact on the individuals' willingness to enter a marriage and accept these obligations, necessitating further regulations of any type of cohabitation. Second, they cannot remove a fundamental loss in utility possibilities that is associated with any dissolution of a partnership through the discontinuation of a productive division of labor and of economies of scale in the joint consumption of household commodities. If they no longer co-operate, the partners may simply become unable to afford their earlier standard of living and their desired number of children. Furthermore, they have any incentive, and probably also many ways, to make sure that the reduced amount of resources is shared asymmetrically between them. Foreseeing this, they may behave exactly as the bargaining approach predicts, even in the presence of external measures meant to stabilize their bargaining positions.

Last but not least, the approach suggested by Cigno (1993), focusing on fertility choices in a model of intertemporal optimization and in the presence of pay-as-you-go pension schemes, definitely offers a case for corrective policy measures. Here, the fiscal externality as the core mechanism which drives the reduction in fertility (and in expenditure per child) is unambiguously distortionary. ${ }^{24}$ Under an unfunded public pension scheme, the decision to bring up a child leads to positive external effects for the rest of society because the contributions to the scheme that the child would make in the future are shared among all (insured) members of the parents' generation. Therefore, unlike with the adjustments in parental decisions discussed thus far, this results in inefficient life-cycle decisions of the individuals affected, including those related to fertility.

While theoretically clear, one may cast doubts as to whether this effect is empirically relevant, for instance, because the relevant elasticities of demand for children and

24 Note that this is not a "real", or "technological", externality which always calls for internalization through taxes or subsidies (Pigou 1932) or through a definition of property rights (Coase 1960). Instead, it is a sub-class of "pecuniary" externalities which, when arising in a system of markets that are functioning well, do not generally create problems, but rather transmit important signals about changes in scarcities. (Note that this applies to the impact of declining fertility on wages and interest rates which are often stressed in the literature on demographic change; see Section 2.2.) By contrast, "fiscal externalities" are associated with the state's monopoly power to tax and, hence, are problematic or "Pareto-relevant". On the taxonomy of externalities and related policy issues, cf. Papandreou (1994). 
child quality could be very low, so that the effect becomes negligible. However, there are a number of empirical studies conforming to current methodological standards and supporting the theoretical prediction in that they find a significant and substantially negative effect of the introduction and expansion of public pay-as-you-go pension schemes on parental fertility decisions, controlling for a host of alternative explanations. $^{25}$ Note, also, that public pensions are usually large programs and that other schemes involving a substantial amount of intergenerational redistribution from the young to the old add to their effect. Hence, the externality may well be substantial. Usually, there are further types of government interventions and fiscal measures, most notably child benefits and publicly subsidized education, which could be expected to reduce the parental cost of having a child and, taken in isolation, should have a positive effect on fertility. However, by the relative size of these programs, they may still not be sufficient to fully off-set the negative impact of public pensions, etc. In the German taxtransfer system, for instance, the size of the fiscal externality of an average child born $2000^{26}$ that is created by the public pension scheme alone has been estimated to be around $€ 140,000$ in terms of a year-2000 present value (Werding and Hofmann 2005); in the entire social insurance system, encompassing public health insurance and longterm care insurance as well, the externality amounts to around $€ 240,000$. Adding tax payments and deducting various types of tax-financed public spending, e.g., on public child care, public education, a host of other child-related benefits and virtually all other items in the general government budget, leaves a fiscal net externality of a new-born child of around $€ 77,000$ - based on a moderate estimate that tries not to overstate the effect wherever there are different options regarding how to quantify single items.

There are thus good reasons to accept that large-scale public interventions in the area of intergenerational distribution have a negative impact on private fertility decisions (and human capital accumulation in general). Ironically, this implies that pay-asyou-go public pension schemes in their traditional form are intrinsically unstable in the sense that they contribute to a long-term erosion of their own tax base.

For a policy that is meant to solve these problems, there are then three major options. First, existing pay-as-you-go pension schemes could be scaled back or even abolished. Taken in itself, however, this does not necessarily restore the incentive for (potential) parents to raise children and spend money on them based on an investment mo-

25 Using different data and very different empirical strategies, this evidence is mainly provided by research groups led by Alessandro Cigno (Cigno and Rosati 1992; 1996; 1997; Cigno et al. 2003), Isaac Ehrlich (Ehrlich and Zhong 1998; Ehrlich and Kim 2005) and Michele Boldrin (Boldrin et al. 2005). No counter-evidence has been produced.

26 Here, "average" refers to gender, life expectancy, educational attainments, labor-force participation and employment throughout the life cycle, and the life-time profile of earnings. 
tive. Also, stabilizing the intergenerational exchange based on some form of a "family constitution" against defection by the young and pooling some of the relevant risks may indeed be a case for public action. Second, existing measures of family policies and public education could be expanded in order to make up for the fiscal externality, thus attempting to off-set negative effects of one public intervention through positive effects of additional interventions. Such a policy is likely to stimulate fertility but, because of the multiple distortions that all kinds of fiscal interventions are likely to create, it is unlikely to neutralize the negative effect of public pensions in a perfect way. Third, public pension schemes as the most important source of the fiscal externality could be redesigned by linking (part of the) individual benefit entitlements to the number of children $^{27}$ and probably also to the income of each child (taken as the most important indicator of returns to parental expenditure per child and other efforts to increase child quality). This third approach goes to the root of the problem and may really solve it - without withdrawing public intervention from the field of old-age provision. ${ }^{28}$

\subsection{Policy instruments}

Actual family policies applied in different countries are probably the most visible examples of instruments which, deliberately or not, are suited to influence parental fertility decisions. Their enormous scope - ranging from legal restrictions on individual behavior in a number of areas to various kinds of fiscal measures - and the richness of their design features are interesting in themselves. Concentrating on fiscal measures and neglecting many details, there are child-related cash benefits and tax allowances, subsidies, vouchers or public provision of specific commodities for children, especially child care and education, child-related components in many more general programs, such as housing allowances, public health care and public pensions (for a very broad survey, see Bradshaw and Finch 2002). Here, there is no room to discuss in full detail how all these elements, and the way they are designed, might be related to the economic rationales for public intervention in the area of fertility decisions.

In the preceding discussion of policy implications of the different approaches to analyzing fertility choices and explaining the fertility decline, three broad categories of policy instruments have been found to be suitable, more or less, to address the issues that turned up, viz. regulation, transfers in kind and financial benefits. The impact of regulation is usually weak, especially if they run counter to long-established habits and

27 In a number of developed countries, public pension schemes already offer some amount of child-related extra benefits. But compared to the size of the fiscal externalities involved in child-rearing, these benefits are small. For a survey and illustrative calculations, see Cigno and Werding (2007, ch. 4).

28 For more detailed proposals of this kind, see Werding (1998, ch. 6), Sinn (2007, ch. 7), or Werding and Cigno (2007, chs. 7 and 8). See also Cigno (2008, this volume). 
norms or if individuals have incentives to circumvent them. Important aspects of how (married) couples interact with each other in the private sphere cannot be meaningfully regulated, even if this were thought to be sensible. ${ }^{29}$ Also, it is doubtful whether several decades of equal-opportunities rules in labor law have really contributed to the expansion of female labor-force participation, or whether the same process would have taken place anyway. At the same time, regarding many aspects, such as gender-related wage differentials or gender proportions in specific professions and occupational levels, there are still huge differences that are not fully explained by women's career choices or exogenous constraints. Similarly, nothing much has changed about the gender-specific division of labor with respect to household production and, most notably, child-care responsibilities. Throughout the developed world, very few men take parental leaves in order to take care of small children. To strengthen the effects of regulation, some countries have added financial incentives, for instance, a limited number of "fathers' months" in child-rearing benefits paid during the first year(s) after a child is born in Sweden, Austria and, most recently, Germany. Special incentives of this kind come close to paternalistic social engineering if men (and women) would make different choices when decisions are left to them. The additional incentives could be defendable, however, if they actually support men vis-à-vis their employers when they ask for a leave and are then able to provide a rational explanation to avoid career disadvantages which are even stronger than in the parallel, but much more typical, case of women.

Financial incentives for compliance with special rules, rather than sanctions against their violation, are already a variant of fiscal measures. Effectively, financial benefits vs. transfers in kind are a major dichotomy of potential policy instruments which can be, and often are, used in existing systems of family policies. Among politicians as well as among researchers, there is considerable disagreement as to which type of measures is more urgently needed and which is likely to prove more effective - while influencing fertility is certainly not the only goal that is to be pursued with these instruments.

Transfers in kind, such as child care (and also schooling and health care for children) at subsidized rates, or entirely for free, are wide-spread. They are probably fashionable because of the strict earmarking of benefits involved - an aspect which, at the same time, requires a special justification. Behind this specific form of transfers, there may again be a variant of paternalism which interferes with parents' spontaneous choices regarding their preferred from of taking care of children, participating in the labor market, etc., unless one specifically stresses the children's interest (ex post, that is, after they are born) and refers to additional problems such as incomplete or asymmetric

29 Exceptions may be given by extreme forms of domestic violence and sexual abuse, but even in these cases, there are limits to observability. 
information. ${ }^{30}$ The earmarking of these benefits may also offer a public choice argument in favor of their use, as there may be broader political support for financing them with a purpose that is fully specified. Usually, recipients (here, parents) should be expected to spend less on this specific item if the same amount of money were transferred instead. All these considerations do not necessarily imply that the state has to become active in providing the relevant services as there are many alternatives, such as subsidies or vouchers, which leave considerable room for competition between private providers.

The basic alternative to providing benefits in kind is to leave even more room for decentralized choices of parents through the provision of financial benefits - assuming that a certain amount of child-related benefits can be justified by the economic models reviewed here before. By the way they are handed out, benefits of this kind are much more neutral with respect to parental choices regarding the way they bring up their children (once they exist) and regarding their own activities, such as participation in the labor market, and so on. Therefore, as long as there are no additional instants of market failure, for instance, in the way parental choices may effect their children's well-being, and as long as there are then no serious doubts that parents are still the best agents of their children, financial transfers appear as the most appropriate form for offering childrelated benefits to potential parents if this is thought to be useful in itself.

A sub-aspect which may become an issue if financial benefits are being justified by fiscal externalities involved in public pensions and other programs of intergenerational redistribution is the appropriate timing of such benefits. Here, it is often argued that delivering benefits in terms of child-related pension benefits is not ideal, as parents would respond more strongly to such benefits, and are more in need of financial support, when their children are still young. Note however, that the idea of a rational lifecycle planning renders the timing of financial benefits less important than one may think. More specifically, if parents can expect to receive (additional) child-related pension benefits when they are old, this has an immediate impact on their financial situation at an earlier stage, since they can adjust their precautionary saving accordingly - which is particularly important if the general level of public pension benefits is to be reduced as a consequence of the budgetary consequences of demographic ageing.

Focusing on the basic question addressed in this paper, viz. the rationale for public intervention that actively targets parental fertility choices, both benefits in kind and financial benefits appear to work, at least at a very superficial glance. This is illustrated in Figures 8 and 9, where total fertility rates in a number of developed countries are confronted with rough summary measures for the size of important sub-categories of both types of benefits. The trend lines included in the two figures are both increasing, indi-

30 See Barr (1993, part 3) and also note 23 above. 
Figure 8: Fertility and child-related financial benefits ${ }^{\text {a) }}$ in OECD countries, 2001

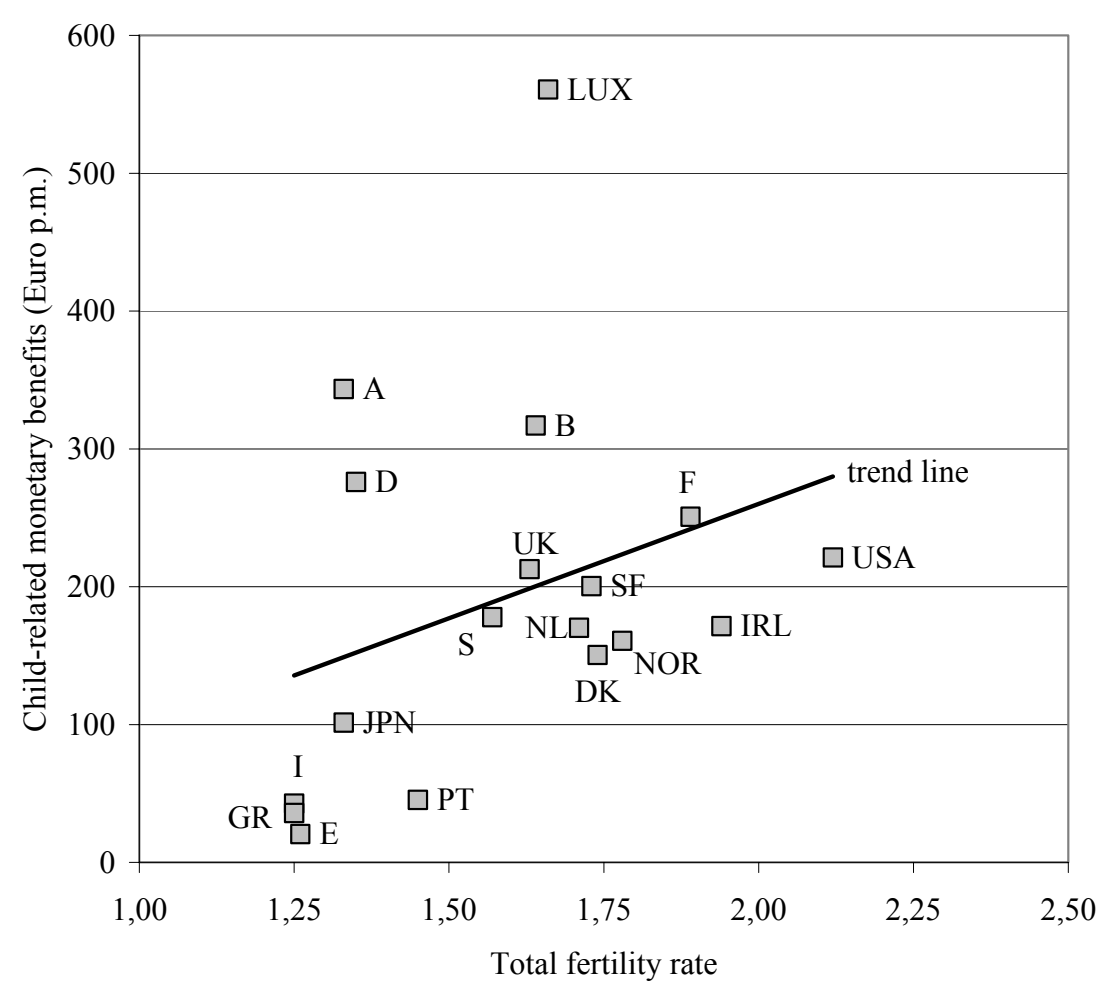

a) Total amounts of monetary benefits paid to couples with two children at a typical level of household income.

Sources: Bradshaw and Finch (2002); Eurostat; national statistical offices.

cating a potential, positive impact on fertility. Of course, these pictures are purely descriptive, that is, they do not imply anything with respect to causality of the observed relationships. Note that, at closer inspection, the data points shown in Figure 8 seem to be more suggestive of a positive impact of financial benefits on fertility than the data points in Figure 9 are of a parallel impact of benefits in kind, specifically child care. This would be largely in line with the literature providing empirical assessments of the effects of child-related policy measures. A number of studies, mainly conducted at a national level for reasons of a proper identification of the benefit systems covered, support the conclusion that financial benefits have a positive impact on fertility. ${ }^{31}$ At the same time, researchers looking into the effects of benefits in kind found it much more difficult to establish a significant, positive effect of the supply of child-care facilities on

31 See, e.g., Laroque and Salanié $(2004 ; 2005)$ with an empirical study for the case of France that is rather advanced in terms of methodology. Similar evidence has been produced by Ermisch (1988a; 1988b) as well as Cigno and Rosati (1996) for the UK; by Sundström and Stafford (1992) as well as Taşiran (1995) for Sweden, and by Cigno et al. (2003) for Germany. Cross-country studies that arrive at the same conclusion have been provided by Blanchet and Ekert-Jaffé (1994) for 11 European countries and by Gauthier and Hatzius (1997) for 22 OECD countries. 
Figure 9: Fertility (2001) and availability of child care (2000) ${ }^{\text {a) }}$ in OECD countries

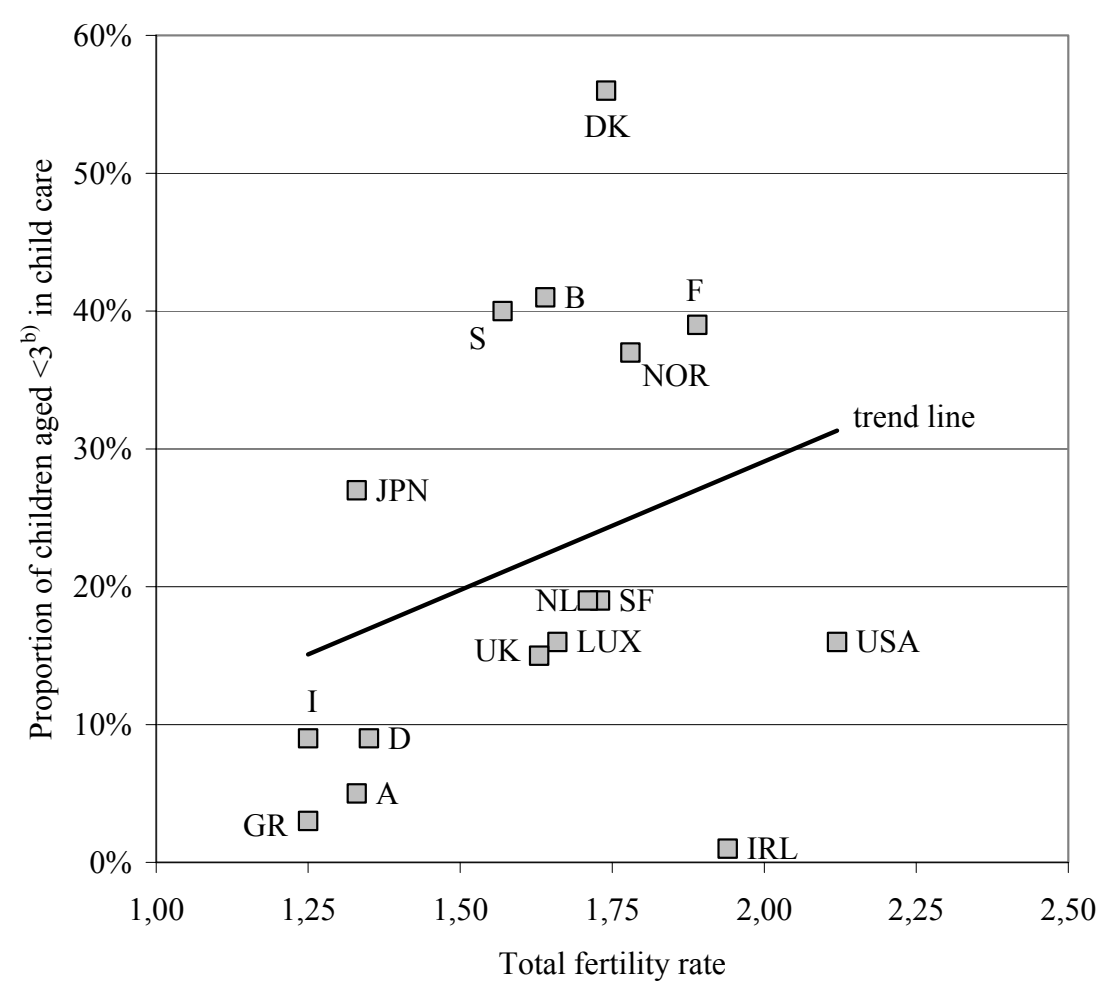

a) Finland, Italy: 1998; Belgium, Japan, Netherlands, Sweden, UK, USA: 1999.

b) Belgium: 3 months to 2.5 year-olds; Ireland: $<4$; Norway: 1-2 year-olds.

Sources: Bradshaw and Finch (2002); Eurostat; national statistical offices.

fertility. ${ }^{32}$ More serious analyses of these questions are also provided or summarized in some of the other contributions collected in this volume (see, e.g., Andersson 2008?; Bradshaw 2008; Cho 2008; or Thévenon 2008).

\section{Conclusion}

In the economic theory of the family, fertility is basically taken to be the result of rational choices of individuals or households that are shaped by the preferences of potential parents as well as by the constraints they are faced with. Against this background, the present paper is devoted to discussing a specific question, namely whether economic analyses of this kind point to reasons why these choices might not be optimal from a

32 See, for instance Hank and Kreyenfeld (2003) or Hank et al. (2004) who investigated this question for Germany, a country with a substantial variation across regions in this respect, due to its system of fiscal federalism. In this case, the cross-country studies done by Castles (2003) as well as Sleebos (2003) for 20 OECD countries have much clearer results that would support a positive effect. 
social perspective, that is, why policy-makers as agents of the public interest should care about their outcomes. In other words, this paper is looking for a normative basis not for family policies in their entirety, but for specific measures that actively target fertility as a goal of public policy, with an eye on increasing low birth rates.

To this end, four differing approaches to explaining the continued fertility decline in developed countries were reviewed in this paper, viz. a quantity-quality interaction involved in decisions on children (Becker 1960; Becker and Lewis 1973); increasing opportunity costs (Willis 1973) and changes in the bargaining situation of partners (Pollak 1985; Ott 1992) associated with child-rearing activities, especially when compared to the alternative of participating in the labor market; and fiscal externalities of bringing up children (Cigno 1986; 1993). The results indicate that, to a considerable degree, the fertility decline may be driven by rational adaptations of potential parents to a changing socio-economic environment. At the same time, they also point to a number of instants for policy intervention that could influence the framework for parental decisions in the labor market and with respect to how (married) couples interact, probably with a positive effect for fertility. At closer inspection, it may turn out to be difficult to exert a strong influence on the behavior of employers or partners through appropriate measures of public policy. What can be done, however, is taking action to mitigate, though probably not remove, conflicts regarding the use of parental time. Given that labor-force participation ranks high in the life-cycle planning of individuals for many reasons which cannot, and often should not, be switched off, improving the opportunities to combine it with parenthood may well be important for a recovery of fertility rates. Designing policies that are suited to meet this task certainly requires careful study of the problems and constraints potential parents are actually faced with. Measures that are likely to be very important in this area relate to the availability of child-care arrangements, while it is less clear whether, and to what extent, these have to be subsidized from public funds.

At the same time, the results of this review also suggest that the fertility decline may be partly a result of ill-designed policy measures in the first place, most notably the large-scale interventions in the field of intergenerational distribution through unfunded pensions and public health insurance schemes. Since these policy tools divert a huge amount of financial resources from families and create a fiscal externality which biases parental fertility choices towards a smaller number of children, appropriate means to solve this problem clearly have a fiscal side. In this case, public policy can either attempt to compensate the adverse effects of existing programs by additional instruments which, taken in isolation, are suited to subsidize children in various ways, or it can try to remove the distortions by re-designing public pension schemes and other existing policy measures. Building on economic research, this, too, should contribute to a recovery of fertility, especially in countries where it has fallen particularly low. 


\section{References}

Andersson, G. (2008), “Zzzzzz”, in: N. Takayama and M. Werding (eds.), Fertility and Public Policy: How to Reverse the Trend of Declining Birth Rates, MIT-Press, Cambridge MA, London, pp. XXX-YYY (this volume).

Apps, P. and R. Rees (2004), "Fertility, Female Labour Supply and Public Policy", Scandinavian Journal of Economics 106, 745-763.

Baland, J.-M. and J.A. Robinson (2000), “Is Child Labor Inefficient?”, in: Journal of Political Economy 108, 663-681.

Barr, N. (1993), The Economics of the Welfare State, Oxford: Oxford University Press.

Becker, G.S. (1960), “An Economic Analysis of Fertility”, in: NBER (ed.), Demographic and Economic Change in Developed Countries, New York and London: Columbia University Press, pp. 209-231.

Becker, G.S. and G. Lewis (1973), “On the Interaction Between Quantity and Quality of Children", Journal of Political Economy 81, S279-S288.

Ben-Porath, Y. (1980), „The F-Connection: Families, Friends, and Firms and the Organization of Exchange“, Population and Development Review 6, 1-30.

Birg, H. (1995), World Population Projections for the $21^{\text {st }}$ Century: Theoretical Interpretations and Quantitative Simulations, Frankfurt and New York: Campus and St. Martin's Press.

Blanchet, D. and O. Ekert-Jaffé (1994), “The Demographic Impact of Family Benefits: Evidence from a Micro-Model and from Macro-Data", in: J. Ermisch and N. Ogawa (eds.), The Family, the Market and the State in Ageing Societies, Oxford: Clarendon Press, pp. 79-104.

Boldrin, M., M. De Nardi and L.E. Jones (2005), "Fertility and Social Security", NBER Working Paper No. 11146.

Bradshaw, J. (2008), “Zzzzzz”, in: N. Takayama and M. Werding (eds.), Fertility and Public Policy: How to Reverse the Trend of Declining Birth Rates, MIT-Press, Cambridge MA, London, pp. XXX-YYY (this volume).

Bradshaw, J. and N. Finch (2002), A Comparison of Child Benefit Packages in 22 Countries, Research Report No. 174, London: Department for Work and Pensions.

Castles, F.G. (2003), "The World Turned Upside Down: Below Replacement Fertility, Changing Preferences and Family-Friendly Public Policy in 21 OECD Countries", Journal of European Social Policy 13, 209-227.

Cho, Y. (2008), “Zzzzzz”, in: N. Takayama and M. Werding (eds.), Fertility and Public Policy: How to Reverse the Trend of Declining Birth Rates, MIT-Press, Cambridge MA, London, pp. XXX-YYY (this volume). 
Cigno, A. (1986), "Fertility and the Tax-Benefit-System: A Reconsideration of the Theory of the Family", Economic Journal 96, 1035-1051.

Cigno, A. (1993), "Intergenerational Transfers without Altruism: Family, Market and State", European Journal of Political Economy 9, 505-518.

Cigno, A. (2008), “Zzzzzz”, in: N. Takayama and M. Werding (eds.), Fertility and Public Policy: How to Reverse the Trend of Declining Birth Rates, MIT-Press, Cambridge MA, London, pp. XXX-YYY (this volume).

Cigno, A., L. Casolaro and F.C. Rosati (2003), "The Role of Social Security in Household Decisions", Finanzarchiv 59, 189-211.

Cigno, A. and F.C. Rosati (1992), "The effects of financial markets and social security on saving and fertility behaviour in Italy", Journal of Population Economics 5, 319341.

Cigno, A. and F.C. Rosati (1996), "Jointly determined saving and fertility behaviour: theory, and estimates for Germany, Italy, UK and USA", European Economic Review 40, 1561-1589.

Cigno, A. and F.C. Rosati (1997), "Rise and fall of the Japanese saving rate: the role of social security and intra-family transfers", Japan and the World Economy 9, 81-92.

Cigno, A. and M. Werding (2007), Children and Pensions, Cambridge, MA, London: MIT-Press.

Coase, R.H. (1960), „The Problem of Social Cost“, Journal of Law and Economics 3, $1-44$.

Ehrlich, I. and J. Kim (2005), "Social security, demographic trends, and economic growth, Theory and Evidence from the international experience", NBER Working Paper No. 11121.

Ehrlich, I.B. and J.-G. Zhong (1998), "Social Security and the Real Economy", American Economic Review 88, 151-157.

Ermisch, J. (1988a), "Econometric Analysis of Birth Rate Dynamics in Britain", Journal of Human Resources 23, 563-576.

Ermisch, J. (1988b), "Economic Influences on Birth Rates", National Institute Economic Review, Issue 4/1988, 71-81.

Feyrer, J. (2007), "Demographics and Productivity", Review of Economics and Statistics 89, 2007, 100-109.

Gauthier, A.H. and J. Hatzius (1997), "Family Benefits and Fertility: An Econometric Model”, Population Studies 51, 295-346.

Hank, K. and M. Kreyenfeld (2003), "A Multilevel Analysis of Child Care and Women's Fertility Decisions in Western Germany", Journal of Marriage and Family 65, 584-596. 
Hank, K., M. Kreyenfeld and C.K. Spieß (2004), "Kinderbetreuung und Fertilität in Deutschland", Zeitschrift für Soziologie 33, 228-244.

Hotz, V.J., J.A. Klerman and R.J. Willis (1997), “The Economics of Fertility in Developed Countries", in: M. Rosenzweig and O. Stark (eds.), Handbook of Population and Family Economics, Vol. 1A, Amsterdam: Elsevier, pp. 275-347.

Kögel, T. (2004), "Did the association between fertility and female employment within OECD countries really change its sign?", Journal of Population Economics 17, 4565.

Laroque, G. and B. Salanié (2004), "Fertility and Financial Incentives in France", CESifo Economic Studies 50, 423-450.

Laroque, G. and B. Salanié (2005), “Does Fertility Respond to Financial Incentives?”, CEPR Discussion Paper No. 5007.

Leibenstein, H. (1957), Economic Backwardness and Economic Growth. Studies in the Theory of Economic Development, New York: John Wiley \& Sons.

Leibenstein, H. (1974), “An Interpretation of the Economic Theory of Fertility: Promising Path or Blind Alley?", Journal of Economic Literature 12, 457-478.

Lindh, T. and B. Malmberg (1999), "Age Structure Effects and Growth in the OECD 1950-1990", Journal of Population Economics 12, 431-449.

Manser, M. and M. Brown (1980), ,Marriage and Household Decision-Making: A Bargaining Analysis“, International Economic Review 21, 31-44.

McElroy, M.B. and M.J. Horney (1981), „Nash-Bargained Household Decisions “, International Economic Review 22, 333-349.

Mitchell, B.R. (2003), International Historical Statistics, 1750-2000 (Europe, The Americas, Africa, Asia and Oceania), $5^{\text {th }}$ Edition, New York: Palgrave MacMillan.

Nugent, J.B. (1985), „The Old-Age Security Motive for Fertility“, Population and Development Review 11, 75-97.

Ott, N. (1992), Intrafamily Bargaining and Household Decisions, Berlin, Heidelberg, New York: Springer.

Papandreou, A.A. (1994), Externality and Institutions, Oxford: Clarendon Press.

Pigou, A.C. (1932), The Economics of Welfare, London: Macmillan.

Pollack, R.A. (1985), "A Transaction Cost Approach to Families and Households", Journal of Economic Literature 23, 581-608.

Razin, A. and E. Sadka (1995), Population Economics, Cambridge, MA, London: MITPress.

Rosenzweig, M.R. and T.P. Schultz (1985), "The Demand and Supply of Births: Fertility and Its Life-cycle Consequences", American Economic Review 75, 992-1015.

Samuelson, P.A. (1975), "The Optimum Growth Rate for Population", International Economic Review 16, 531-538. 
Samuelson, P.A. (1976), "The Optimum Growth Rate for Population: Agreement and Evaluations", International Economic Review 17, 516-525.

Sinn, H.-W. (2000), "Why a Funded Pension System is Useful and Why It is Not Useful”, International Tax and Public Finance 7, 389-410.

Sinn, H.-W. (2001), "The Value of Children and Immigrants in a Pay-As-You-Go Pension System", ifo Studien 47, 77-94.

Sinn, H.-W. (2007), Can Germany Be Saved? The Malaise of the World's First Welfare State, Cambridge, MA, London: MIT-Press.

Sleebos, J.E. (2003), "Low Fertility Rates in OECD Countries: Facts and Policy Responses", OECD Social, Employment and Migration Working Paper No. 15.

Sundström, M. and F.P. Stafford (1992), "Female Labor Force Participation, Fertility and Public Policy in Sweden", European Journal of Population 8, 199-215.

Taşiran, A.C. (1995), Fertility Dynamics: Spacing and Timing of Births in Sweden and in the United States, Amsterdam: Elsevier.

Thévenon, O. (2008), “Zzzzzz”, in: N. Takayama and M. Werding (eds.), Fertility and Public Policy: How to Reverse the Trend of Declining Birth Rates, MIT-Press, Cambridge MA, London, pp. XXX-YYY (this volume).

Werding, M. (1998), Zur Rekonstruktion des Generationenvertrages, Tübingen: MohrSiebeck.

Werding, M. (2007), “Ageing, Productivity and Economic Growth: A Macro-level Analysis", Hitotsubashi University, Tokyo, PIE-CIS Discussion Paper No. 338.

Willis, R.J. (1973), "A New Approach to the Economic Analysis of Fertility Behavior", Journal of Political Economy 81, S14-S64. 